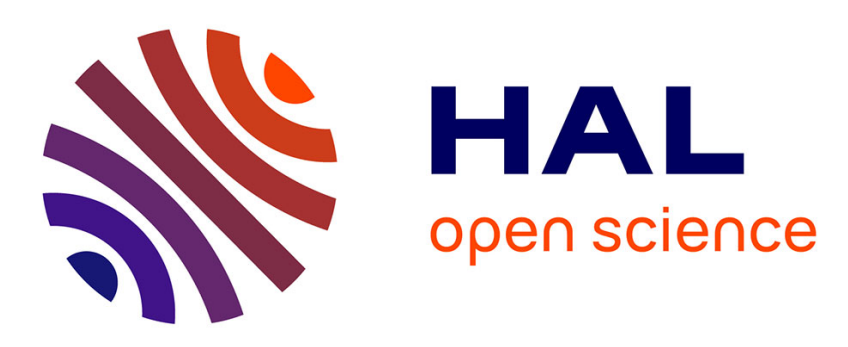

\title{
Radical Anions of Oxidized vs. Reduced Oxytocin: Influence of Disulfide Bridges on CID and Vacuum UV Photo-Fragmentation
}

Luke Macaleese, Marion Girod, Laurent Nahon, Alexandre Giuliani, Rodolphe Antoine, Philippe Dugourd

\section{To cite this version:}

Luke Macaleese, Marion Girod, Laurent Nahon, Alexandre Giuliani, Rodolphe Antoine, et al.. Radical Anions of Oxidized vs. Reduced Oxytocin: Influence of Disulfide Bridges on CID and Vacuum UV Photo-Fragmentation. Journal of The American Society for Mass Spectrometry, 2018, 29 (9), pp.18261834. 10.1007/s13361-018-1989-8. hal-01864504

\author{
HAL Id: hal-01864504 \\ https://hal.science/hal-01864504
}

Submitted on 31 Oct 2020

HAL is a multi-disciplinary open access archive for the deposit and dissemination of scientific research documents, whether they are published or not. The documents may come from teaching and research institutions in France or abroad, or from public or private research centers.
L'archive ouverte pluridisciplinaire HAL, est destinée au dépôt et à la diffusion de documents scientifiques de niveau recherche, publiés ou non, émanant des établissements d'enseignement et de recherche français ou étrangers, des laboratoires publics ou privés. 
* Title page

Radical anions of oxidized vs. reduced Oxytocin: influence of disulfide bridges on CID and direct Vacuum UV photo-fragmentation. Do disulfide bridges protect from direct Vacuum UV radiation damage?

Luke MacAleese(1), Marion Girod(2), Laurent Nahon(3), Alexandre Giuliani(3,4), Rodolphe Antoine(1), Philippe Dugourd(1)

(1) Université de Lyon, CNRS, Université Claude Bernard Lyon 1, Institut Lumière Matière UMR 5306, F-69622, VILLEURBANNE, France

(2) Université de Lyon, CNRS, Université Claude Bernard Lyon 1, ENS de Lyon, Institut des Sciences Analytiques UMR 5280, F-69100, VILLEURBANNE, France

(3) Synchrotron SOLEIL, BP 48 St Aubin, F-91192 Gif Sur Yvette, France

(4) UAR1008 CEPIA, INRA, BP 71627, FR-44316 Nantes, France

\section{* Abstract}

The nona-peptide Oxytocin (OT) is used as a model sulfur-containing peptide to study the damage induced by vacuum UV (VUV) radiations. In particular, the effect of the presence (or absence in reduced OT) of oxytocin's internal disulfide bridge is evaluated in terms of photo-fragmentation yield and nature of the photo-fragments. Intact as well as reduced OT are studied as dianions and radical anion species. Radical anions are prepared and photo-fragmented in two-color experiments (UV+VUV) in a linear ion trap. VUV photo-fragmentation patterns are analyzed and compared, and radical-induced mechanisms are proposed. The effect of VUV is principally to ionize, but secondary fragmentation is also observed. This secondary fragmentation seems to be considerably enabled by the initial position of the radical on the molecule. In particular, the possibility to form a radical on free cysteines seems to increase the susceptibility to VUV fragmentation. Interestingly, disulfide bridges, which are fundamental for protein structuration structure, could also be responsible for an increased resistance to ionizing radiations. 


\section{INTRODUCTION}

The underlying processes in biomolecules activated by high-energy photons, in particular in the vacuum UV/VUV radiation, are of tremendous importance in radiation science.[1, 2] Radical formation on biomolecules is often observed following high-energy photon irradiation, either due to direct homolytic cleavage or to radical transfer involving solvent molecules.[3] Radical cations are important sources of damage to DNAs[4] and are major ingredients in photo-oxidation of proteins.[5] Phenoxyl and indolyl radicals are ubiquitous in protein science: these radicals favor long-distance charge transport[6-9] and propagation of radical damage in proteins.[10, 11] For instance, tryptophan photolysis, through photoinduced electron transfer to nearby disulfide bridges, may induce disulfide reduction leading to a thiolate and a thiyl radical.[12] Thiyl radicals can also be produced via a direct light-induced homolysis of cystine disulfide bonds, $[13,14]$ Ultimately, thiyl radical mediated damage to proteins may lead to protein aggregation and fragmentation, for example in antibodies. $[15,16]$ Thus probing photoprocesses in thiyl radical containing biomolecules activated by vacuum UV (VUV) radiation is required to improve would help improving our knowledge in radiation damage science.

Electron capture or electron transfer approaches (ECD/ETD), applied to multiply protonated peptides, were widely reported to dissociate disulfide bridges into a thiol and a thiyl radical.[17] Gas phase experiments using collision induced dissociation coupled to ion trap mass spectrometry isrepresent another useful approach to generate thiyl radicals by dissociation of S-nitrosylated homocysteine compounds. $[18,19]$ Light can also be used to generate cysteine radicals from modified peptides in the gas phase. [20] A similar approach was used by Julian et al. with quinone-substituted cysteines, although, in this latter case, the photo-induced radical is located on cysteine $C_{\beta}$, and the sulfur is lost. [21] In a previous work, we reported vacuum UV spectroscopic investigations on phenoxyl and indolyl radicals formed by direct irradiation of the non-modified peptide by UV laser pulses. [22] Neutral indolyl and phenoxyl radicals were generated in the gas phase by using electron photodetachment from WVVVV (and YVVVV) doubly deprotonated peptides, the C-terminal carboxyl group was a deprotonation site and the second deprotonation occurred on the nitrogen of the indole (and the oxygen of tyrosine's phenol) ring. Electron detachment from this deprotonated ring led to the formation of an indolyl (and a phenoxyl) radical, which were further irradiated by a VUV light using synchrotron radiation. Following the same two colors experiment scheme, we aim at producing thiyl radicals in a model sulfur-containing peptide anion and investigating their VUV induced fragmentation.

In this study, we aimed at understanding the influence of disulfide bridges and their reduction on the stability of cysteine-containing peptides upon VUV irradiation. The formation of a radical by electronphoto-detachment on a gas-phase peptide results in specific fragmentation. But, while multiple mechanisms were proposed and tested in the case of radical cations, in particular the dissociation of disulfide bridges by ECD/ETD, [17] much less is known from radical anions. The reason probably has to do with the higher instability of anions towards electron emission and spontaneous fragmentation brings some experimental complexity, while theoretical chemistry of negatively charged species is also very challenging, set aside the issue of radicals and unpaired electrons. In this study, we use oxytocin (OT) as a model sulfur-containing peptide. Oxytocin is a nona-peptide hormone with an internal disulfide bridge and amidated C-termC-terminus, known to be active in various physiological processes and critical for cell-signaling mechanisms. [23] Photo-degradation in the UV range of oxytocin and the thermal stability of its photoproducts have been studied by Mozziconacci and Schöneich in solution. [24] The formation, reactivity and lifetime of disulfide radicals was also 
reported earlier in solution. $[25,26]$ In this study we present results of VUV photo-fragmentation spectroscopy of radicals, generated from both oxidized and reduced forms of Oxytocin isolated in the gas phase. CID and VUV patterns are compared in order to draw mechanistic conclusions. Several fragmentation schemes are proposed to explain the major features and differences between the VUV photo-dissociation spectra of reduced and non-reduced Oxytocin. We discuss the initial position of the charge and the radical as a function of the presence of the disulfide bridge. We comment on the fragmentation patterns observed for oxytocin radical anions as a result of this initial radical position.

\section{EXPERIMENTS AND METHODS}

Sample. Oxytocin acetate salt hydrate (Sigma-Aldrich, St Quentin-Fallavier, France) was dissolved in water and diluted in acetonitrile (ACN), to reach a concentration of $30 \mu \mathrm{M}$ in H2O:ACN (1:1). OT is sold in its oxidized form (OTSS). In order to obtain the reduced form (OTSH), the reducing agent tris(2-carboxyethyl)phosphine hydrochloride (TCEP, Sigma-Aldrich) was added to the solution at a 10 -fold excess with regards to oxytocin. The resulting OTSS/OTSH solutions were used as is in the ESI source of the mass spectrometers.

OT singly charged anions: high resolution mass spectrometry. The collision induced dissociation (CID) spectra of singly charged anions ([OTSS $]^{-}$and [OTSH] $]^{-}$) were measured on a QExactive mass spectrometer (Thermo). The monoisotopic peaks at $\mathrm{m} / \mathrm{z} 1005.4$ and 1007.4 were selected with a window width of $m / z 1$ and activated in the HCD cell with collision energies (CE) ranging from $2 \mathrm{eV}$ to $40 \mathrm{eV}$. The mass spectra presented below correspond to a CE of $40 \mathrm{eV}$. CID mass spectra were recorded on the mass range $[75 ; 1200]$ with a resolution of 140000.

OT dianions and radicals: CID and VUV photodissociation. The CID spectra of oxytocin dianions (OTSS and OTSH) as well as their singly charged radical anion counterpart (OTSS and OTSH) were recorded in a LTQ XL linear ion trap mass spectrometer (Thermo). For CID, the dianions were mass selected ( $\mathrm{m} / \mathrm{z} 502$ and 503 for OTSS and OTSH respectively) and activated with a "normalized collision energy" (NCE) of 15. The "Act Q" parameter was always kept at 0.25 (default) at all times. In order to generate radical anions, the mass-selected dianions were mass-isolated and subjected to $266 \mathrm{~nm}$ irradiation ( $4^{\text {th }}$ harmonic of Nd:YAG $-6 \mathrm{~mJ}, 20 \mathrm{~Hz}$, Brilliant A, Quantel). The dianions activation time was set to $600 \mathrm{~ms}$, while keeping the NCE to 0 . After irradiation at $266 \mathrm{~nm}$, the radical anions formed by electron detachment are mass selected (window $\mathrm{m} / \mathrm{z} 1$ ) and activated with NCE ranging from 25 to 35 .

Vacuum UV fragmentation of the dianions and radicals was recorded on the same instrument (LTQ $\mathrm{XL}$ ), that is coupled [27] to the DESIRS beamline[28] at the SOLEIL synchrotron radiation facility (France). For the VUV photodissociation experiments for dianions and radicals, instead of applying collisional activation, NCE was set to 0 and the activation time was set to $600 \mathrm{~ms}$ during which the Vacuum UV beam of the synchrotron was injected on axis in the LTQ ion trap on the selected ions (Scheme 2). Practical details of the UV and VUV combination (via a mirror with a central hole) and coupling to the mass spectrometer can be found in prior publications.[29, 30] The synchrotron beam, passing through a $500 \mu \mathrm{m}$ monochromator slit, was filtered by an MgF2 window (below $9 \mathrm{eV}$ ) and an Ar-filled gas filter (8-16 eV) in order to suppress the high harmonics of the undulator. Thus harmonicfree monochromatized VUV radiation was used to irradiate ions with a $12 \mathrm{meV}$ bandwidth. The fragmentation ratio presented as inset in Fig. 1-4 are defined as " $1-I_{\text {parent }} / T I C$ ", with $I_{\text {parent }}$ the intensity of the parent ion and TIC the total ion current. They are not corrected for the VUV photon flux (Figure S5). 


\section{RESULTS}

The VUV photo-dissociation spectra of oxidized and reduced OT dianions, as well as of their associated singly-charged radical created by electron photo-detachment, were recorded over the 4.5-16 eV range.

Figure 1 and Figure 2 present the VUV photo-dissociation mass spectra of respectively OTSS and OTSH dianions averaged over the whole VUV range. The main One major feature in both cases is electron detachment, yielding the radical anions [OTSS] ${ }^{*-}(m / z ~ 1004)$ and [OTSH] ${ }^{*-}(m / z ~ 1006)$. This initial electron detachment is followed by radical induced fragmentation of the resulting radical anions, as described below.

In OTSS, the fragment ions observed at $\mathrm{m} / \mathrm{z} 971.2$ and $\mathrm{m} / \mathrm{z} 939.3$ could result from neutral losses of $33 \mathrm{Da}$ and $65 \mathrm{Da}$ corresponding to $\mathrm{SH}^{\circ}$ (Scheme S1) and $\mathrm{S}_{2} \mathrm{H}^{\bullet}$ (Scheme 3) from the radical precursor. These mechanisms require first the $\mathrm{H}$ abstraction from either $\mathrm{Cys}_{\alpha} \mathrm{C}_{\alpha}$ or $\mathrm{C}_{\beta}$ by the tyroxy-radical, as previously reported by Beauchamp and coworkers,[31] which is associated with the transfer of the radical on Cystein $\mathrm{C}_{\alpha}$ or $\mathrm{C}_{\beta}$. This allows the radical-induced cleavage of the disulfide bridge and the radical elimination of $\mathrm{SH}^{\bullet}$ and $\mathrm{S}_{2} \mathrm{H}^{*}$. This latter loss suggests that in the OTSS radical, the disulfide bridge is conserved. Four other intense C-term fragments are observed at $m / z$ 898.2, $m / z$ 886.2, $m / z$ 853.3 and $m / z$ 369.1. These ions are observed in the CID spectrum of the radical anion (Figure S3), but not of the non-radical specie (Figure S1). They are thus produced by radical-induced fragmentation. The $m / z 898.2$ ion could arise from the radical-induced elimination of the tyrosine sidechain (Scheme S2). This confirms the initial position of the radical on supports the hypothesis that the radical is initially formed on tyrosine. The ion detected at $m / z 369.1$ corresponds to fragment $\mathrm{z}_{4}$ and could be produced, after $\mathrm{H}$ abstraction from $\mathrm{Cys}_{\mathrm{s}} 6 \mathrm{C}_{\beta}$, by the radical-induced cleavage of the $\mathrm{N}-\mathrm{C}$ bond between Asn5 and Cys6, concertedtogether with the $1,3 \mathrm{H}$ transfer from the $\mathrm{Cys}_{1} \mathrm{C}_{\beta}$ to Cys6 sulfur (Scheme S3). When considering the $\mathrm{H}$ abstraction from $\mathrm{Cys}_{1} \mathrm{C}_{\beta}$, the radical-induced cleavage of the $\mathrm{N}-\mathrm{C}$ bond of Tyr2 concertedassociated with the $1,3 \mathrm{H}$ transfer from the Cys $6 \mathrm{C}_{\beta}$ to Cys1 sulfur (Scheme 4) could yield the radical ion detected at $m / z$ 886.2. Eventually, following $H$ abstraction by the tyroxy-radical from Cys6 $C_{\alpha}$, the ion at $m / z 853.3$ may arise from the radicalinduced cleavage of $\mathrm{Cys}_{6} \mathrm{C}_{\beta}$-S bond, concerted with the $1,3 \mathrm{H}$ transfer from Tyr2 $\mathrm{C}_{\beta}$ to Tyr2 backbone nitrogen (Scheme 5).

Remarkably, the relative intensity of the tyrosine sidechain loss is high in the VUV photo-dissociation (VUVPD) mass spectrum of the dianions while it is comparably lower in the CID spectrum of the OTSS radical in Figure $\mathrm{S} 3$. This supports the hypothesis that the radical created on the tyrosine is moving over the backbone: in the VUVPD of the OTSS dianion, fragmentation may occur immediately after the electron detachment, without radical scrambling due to collisional activation. Thus, the radical may remain localized longer on tyrosine, hence the favored local radical fragmentation pathway.

For the OTSH dianion (Figure 2), the loss of $\mathrm{NH}_{3}$ and $\mathrm{SH}^{\bullet}$ are predominant in the VUV photodissociation spectrum. Although $\mathrm{NH}_{3}$ loss can also be reported in non-radical species, the intensity of those particular fragments is significantly enhanced in the CID spectrum of the radical species. Thus it is hypothesized that they are both generated via radical induced mechanisms (Scheme $\mathrm{S} 4$ and Scheme 6), in particular the loss of $\mathrm{NH}_{3}$ which is specifically observed in the CID spectrum of the OTSH radical (Figure S4) but not of the non-radical anion (Figure S2). Two intense fragments are also observed on the VUVPD mass spectrum: $b_{5}$ and $c_{5}$. Fragment $b_{5}$ could originate from the radical induced cleavage of the amide bond between Asn 5 and Cys 6 following the $\mathrm{H}$ abstraction on Asn $5 C_{\alpha}$ by radical sulfur on Cys6 (Scheme 7). Fragment $C_{5}$ could originate from the Cys $6 \mathrm{~N}-\mathrm{C}$ bond cleavage concerted with the $\mathrm{S}-\mathrm{O}$ bond formation between Cys 6 radical sulfur and 
carbonyl, and the $1-5 \mathrm{H}$ transfer from Cys6 $\mathrm{C}_{\beta}$ to Asn5 carbonyl (Scheme S5), similar to the mechanism reported for electron detachment dissociation on cystein-containing peptides.[32] Interestingly, the $\mathrm{NH}_{3}$ loss involves a radical on Cys1 whereas the $\mathrm{b}_{5}$ and $\mathrm{c}_{5}$ fragments involve a radical on Cys6. This suggests that the radical can be equally formed on both cysteins from OTSH dianion. In any case, this confirmsprovides evidence for the formation of a thiyl radical upon VUV irradiation (and thus for the position of the charges on the free cysteines in the dianions). The fragmentation ratios of the dianions are similar: weak, but increasing with the photon energy (see insets in Figure 1 and Figure 2).

Figure 3 and Figure 4 present the VUV photo-dissociation mass spectra of the radical anions formed by electron detachment from OT dianions : respectively [OTSS] ${ }^{-}$and [OTSH] $]^{\bullet}$. In contrast to dianions, electron photo-detachment leads to neutral species, which cannot be observed. Thus the observed charged fragments result from a competition between fragmentation and photodetachment. Nevertheless, the fragments observed are also consistent with the major fragments in the CID of radical species (see above and $\mathrm{SI}$ ). For OTSS, the three radical induced fragments at $m / z 898,886$ and 853 are still present and the relative intensity of tyrosine's sidechain loss is weak and similar to the one obtained by CID. Comparably, the neutral losses $\mathrm{S}_{2} \mathrm{H}^{\circ}$ at $\mathrm{m} / z 939$ is dominant as in the CID spectrum (Figure S3), which supposedlywe hypothesize involves the shift of the radical from tyrosine to Cys1 $C_{\alpha}$ (Scheme 3 ). The fragmentation ratio of OTSS radical anion is very weak, close to the spontaneous fragmentation level, and does not significantly increase with the photon energy (Figure 3 - inset).

For OTSH (Figure 4) the two radical-induced mechanisms leading to the loss of $\mathrm{NH}_{3}$ and $\mathrm{SH}^{\bullet}$ are again predominant, confirmingsupporting the presence and reactivity of thiyl radicals. No other fragment is significantly populated, so that all the fragmentation is generated around the radical centers on sulfur. The overall VUV fragmentation ratio is very high - around $25 \%$ (Figure 4 - inset), and close to the spontaneous fragmentation level. It slightly decays with increasing photon energy.

\section{DISCUSSION AND CONCLUSIONS}

In oxytocin, since the C-term is amidated, the most acidic sites are the free thiols (pKa 8.2-9.5) in OTSH and tyrosine (pKa 10.4) in OTSS. Thus, when the disulfide bridge is reduced, the free cysteines are the preferential sites for deprotonation. Given the low ionization energy of thiolates ( $2 \mathrm{eV}[32]$ ), even a low energy photon might form a radical by electron photo-detachment from anionic cysteines. In the non-reduced oxytocin, the most probable site for deprotonation is tyrosine (a second deprotonation must occur on the backbone in the dianion). Here again, considering the low ionization energy of tyrosinate ( $2.2 \mathrm{eV}[32])$, the radical will be formed on tyrosine. The fragmentation patterns observed confirmare consistent with those localizations of the radicals, in particular the loss of the tyrosine sidechain in OTSS. However, the nature of fragments also indicates that the radical on tyrosine seems to be mobile and prone to move to the backbone via $\mathrm{H}$-abstraction e.g. from Cys $1 / \mathrm{Cys}_{\mathrm{s}} \mathrm{C}_{\alpha}$ or $\mathrm{C}_{\beta}$, leading to the appearance of intense radical induced fragments far from tyrosine, including $\mathrm{SH}^{\circ}$ and $\mathrm{S}_{2} \mathrm{H}^{\circ}$. Remarkably, the latter fragmentation is only observed from nonreduced OT and may reflect the presence of an intact disulfide bridge, consistent with the proposed formation mechanism. This indicates that the absorption of photons at $266 \mathrm{~nm}$ is not necessarily followed by the homolytic cleavage of existing disulfide bridges, in contrast to what was reported for positively charged ions[33]. In order to understand this difference, it is worth looking for comparison, at the mechanisms proposed to explain the S-S radical-induced bond cleavage by ECD/ETD in protonated peptides (see ref 307-309 in [17]). All require proton-rich species: either neighboring 
positive charges induce the coulomb stabilization of the S-S $\sigma^{*}$ orbital, which enables the direct capture of an electron by the disulfide bridge and its cleavage into thiyl and thiolate (the latter neutralized by an intramolecular proton transfer) ; or the electron attachment to a neighboring protonated site is followed by a $\mathrm{H}$-atom transfer from the radical site to the disulfide bridge, inducing its barrierless cleavage into thiol and thiyl. In contrast however, Oxytocin anions are depleted in protons. The electron detachment occurs preferentially from the deprotonated tyrosine, thus there is no $\mathrm{H}$ available to transfer the radical away. As shown above, direct tyrosine radical fragmentation is observed. However, there is more than this fragmentation path, and the other fragments require different positions of the radical. The only possibility to shift the radical position away from tyrosine is a $\mathrm{H}$-atom "back transfer" to the radical, which can only take place from $\mathrm{H}$-containing sites, in particular the backbone. The OTSS radical fragmentation schemes proposed (Scheme 3 to Scheme 5) start from radical positions on the backbone that implicitly incorporate an initial $\mathrm{H}$-atom transfer to tyrosine. It is worth noting that the long VUV irradiation time opens the possibility for many rearrangements and possibly other radical re-localization on the backbone. Thus, the proposed fragmentation mechanisms represent one possibility to reach the observed fragments. In the case of OTSH and thiyl radicals, on the contrary, the reactivity leading to local fragmentation seems to exceed possible intramolecular $\mathrm{H}$-transfer such that no other radical-induced fragments are observed.

From CID analysis in the negative mode (see $\mathrm{SI}$ ), the presence of the disulfide bridge of OTSS is supported by series of specific fragments[34, 35], in particular the $\mathrm{S}_{2} \mathrm{H}_{2}$ loss on the parent peptide $\left(\mathrm{S}_{2} \mathrm{H}^{\bullet}\right.$ loss for the radical) and the $-2.016 \mathrm{Da}$ shift on usual b-/c-/y-type fragments. Remarkably, the 2.016 Da shift does not appear in the OTSS radical. This can be explained by the more reactive radical induced fragmentation mechanisms that decrease the proportion of classical backbone fragments. From the presence of those specific fragments, it can be reasonably inferred that Using those specific fragments, it is shown that the disulfide bridge is conserved in OTSS radical anion.

The analysis of the VUV photo-dissociation of oxytocin dianions indicates that their fragmentation is predominantly driven by the radical, as understood from fragmentation patterns similar to the CID of radical anions - significantly different from non-radical anions. This is expected since the CID spectra of the radical species was already showing the same trend. From this, it can be deduced that the absorption of VUV photons first induces electron detachment, and then the remaining internal energy may leads to the fragmentation of the radical. All the fragmentation mechanisms proposed (Scheme 3 to Scheme 7 and Scheme S1 to Scheme S5) start from the radical species. However, in terms of total fragmentation yield (including electron detachment), both OTSS and OTSH dianions are comparable, indicating that the presence of the disulfide bridge has surprisingly no major effect on the disappearance of dianions. Since the ionization energy of thiolate and tyrosynate are very close, no major difference was expected in terms of electron detachment. However, it can be noted that the relative abundance of the radical OT anion vs. fragments is drastically different: high in the case of OTSS and low for OTSH. This suggests that the radical anion of Oxytocin is more prone to fragment when the disulfide bridge is open. This is consistent with the spontaneous fragmentation levels or radical anions measured without VUV. Eventually, in both cases, the increase of photon energy opens new ionization routes, reflecting in increased VUV photo-detachment cross section and as a result, increased secondary fragmentation.

Turning to the VUV fragmentation of radicals, one might observe that [OTSH] "- present a considerably higher fragmentation ratio than [OTSS] ${ }^{*-}$ and the dianions. As mentioned above, this is consistent with the very high spontaneous fragmentation ratio observed for OTSH radical (respectively low for OTSS radical). This represents the most striking difference between OTSS and OTSH radicals. One 
might argue that the low apparent fragmentation of [OTSS] ${ }^{--}$is due to invisible backbone fragmentations because of the presence of the disulfide bridge keeping fragments together. However, there is neither backbone fragmentation in the VUVPD spectrum of [OTSH] ${ }^{*}$ nor in the CID spectrum of [OTSS] ${ }^{*}$. Thus, the hypothesized presence of a disulfide bridge is not likely to artificially lower the apparent fragmentation ratio of [OTSS $]^{\circ}$. On the contrary, 2 other observations can be made: on the one hand, the comparison with CID spectra of non-radical anions suggests that the fragmentation of both OT radicals is essentially radical driven. On the other hand, fragmentation patterns are very different for [OTSS $]^{-*}$ vs. [OTSH ${ }^{*}$, which suggests that the initial position of the radical in the anions - hypothesized on cysteine for OTSH but on tyrosine or the backbone in OTSS is responsible for the nature of the fragments. Thus, the difference in fragmentation level between [OTSS] ${ }^{*-}$ and [OTSH] ${ }^{-*}$ most likely reflects the different intrinsic reactivity associated with the actual radical position in OT.

In terms of particular effects of VUV radiations on the radicals, it is worth reminding that the major effect of VUV is to ionize, as illustrated by the VUVPD mass spectrum of dianions. However, the ionization of radical anions yields neutral products. Thus, what is observed for radical anions is how spontaneous fragmentation is affected by VUV radiations. For OTSS radical, no effect particular effect is noticed: branching ratios remain constant and the overall fragmentation level remains very close to its spontaneous level. In the case of OTSH radical, however, the fragmentation level decreases with photon energy. The ionization cross section increases with VUV photon energy, as illustrated by the evolution of dianions VUV photo-detachment/fragmentation yield. It seems that the ionization cross section of OTSH radical anion increases less rapidly than that of its fragments, resulting in the overall decrease of the apparent fragmentation ratio as a function of photon energy.

In conclusion, the analysis of the fragmentation patterns of oxytocin in both its reduced and nonreduced forms, for the anionic and radical anionic species, enabled the interpretation of the VUV photo-fragmentation spectra. Analyzing the nature of VUVPD fragments, it is significant that VUV fragments are identical to the major radical-induced fragments observed by CID: this suggests that the fragmentation does not occur in the excited state, but rather after redistribution of the energy deposited by either electron photon-detachment or collisions. The effect of VUV is, as expected, principally to ionize. Then, consecutive (secondary) fragmentation can be observed, as proven by the exclusive observation of radical directed fragments. This secondary fragmentation is considerably enabled by the initial position of the radical, and the nature of the fragments reflects the intrinsic fragmentation reactivity associated to the position of this radical. In particular, thiyl radicals seem to very efficiently lead to $\mathrm{NH}_{3}$ and $\mathrm{SH}^{*}$ loss in Oxytocin, whereas the tyroxyl radical is prone to induce an intramolecular $\mathrm{H}$-transfer and seems to be less efficiently coupled to a specific fragmentation path. Thus the presence of the disulfide bridge does not seem so much to influence per se Oxytocin's susceptibility to photo-fragment. However, the possibility to form a radical on free cysteines seems to increase the susceptibility of reduced oxytocin to photo-fragment after photo-ionization in the VUV. Interestingly, disulfide bridges, which are fundamental for protein structuration, could also be responsible for an increased resistance to ionizing radiations. Or, more precisely, denatured proteins with reduced disulfide bridges and free cysteines could be more sensitive to radiation damages via the photo-generation of reactive cysteine radicals.

\section{- Acknowledgment}

Research leading to these results received funding from the European Research Council under the European Union's Seventh Framework Programme (FP7/2007-2013 Grant agreement No. 320659). 
SOLEIL support is acknowledged under project no. 20120093. We also thank the general technical staff of SOLEIL for running the facility. This research was supported by the Agence Nationale de la Recherche Scientifique, France, under the project \#BLAN08-1_348053.

\section{* References}

1. O'Neill, P., Wardman, P.: Radiation chemistry comes before radiation biology. Int. J. Radiat. Biol. 85, 9-25 (2009). doi:10.1080/09553000802640401

2. Görner, H.: Photochemistry of DNA and related biomolecules: yields and consequences of photoionization. J. Photochem. Photobiol. B. 26, 117-139 (1994). doi:10.1016/10111344(94)07068-7

3. Wien, F., Miles, A.J., Lees, J.G., Vrønning Hoffmann, S., Wallace, B.A.: VUV irradiation effects on proteins in high-flux synchrotron radiation circular dichroism spectroscopy. J. Synchrotron Radiat. 12, 517-523 (2005). doi:10.1107/S0909049505006953

4. Giese, B.: Electron transfer in DNA. Curr. Opin. Chem. Biol. 6, 612-618 (2002). doi:10.1016/S1367-5931(02)00364-2

5. Davies, M.J., Truscott, R.J.W.: Photo-oxidation of proteins and its role in catractogenesis. J. Photochem. Photobiol. B. 63, 114-125 (2001)

6. Giese, B., Napp, M., Jacques, O., Boudebous, H., Taylor, A.M., Wirz, J.: Multistep electron transfer in oligopeptides: Direct observation of radical cation intermediates. Angew. Chemie Int. Ed. 44, 4073-4075 (2005). doi:10.1002/anie.200500391

7. Aubert, C., Vos, M.H., Mathis, P., Eker, A.P.M., Brettel, K.: Mechanism of radical transfer during photoactivation of the flavoprotein DNA photolyase. Nature. 405, 586-590 (2000)

8. Stubbe, J.A., Nocera, D.G., Yee, C.S., Chang, M.C.Y.: Radical initiation in the class I ribonucleotide reductase: Long-range proton-coupled electron transfer? Chem. Rev. 103, 2167-2201 (2003). doi:10.1021/cr020421u

9. Mishra, A.K., Chandrasekar, R., Klapper, M.H., Faraggi, M.: Long-range Electron Transfer in Peptides. Tyrosine Reduction of the Indolyl Radical: Reaction Mechanism, Modulation of Reaction Rate, and Physiological Considerations. J. Am. Chem. Soc. 116, 1414-1422 (1994). doi:10.1021/ja00083a029

10. Dean, R.T., Hunt, J. V., Grant, A.J., Yamamoto, Y., Niki, E.: Free radical damage to proteins: The influence of the relative localization of radical generation, antioxidants, and target proteins. Free Radic. Biol. Med. 11, 161-168 (1991). doi:10.1016/0891-5849(91)90167-2

11. Hawkins, C.L., Davies, M.J.: Generation and propagation of radical reactions on proteins. Biochim. Biophys. Acta - Bioenerg. 1504, 196-219 (2001). doi:10.1016/S0005-2728(00)002528

12. Haywood, J., Mozziconacci, O., Allegre, K.M., Kerwin, B.A., Schöneich, C.: Light-induced conversion of trp to gly and gly hydroperoxide in IgG1. Mol. Pharm. 10, 1146-1150 (2013). doi:10.1021/mp300680c

13. Creed, D.: The photophysics and photochemistry of the near-UV absorbing amino-acids - III. Cystine and its simple derivatives. Photochem. Photobiol. 39, 577-583 (1984). doi:10.1515/semi.2000.128.1-2.113

14. Everett, S.A., Schöneich, C., Stewart, J.H., Asmus, K.D.: Perthiyl radicals, trisulfide radical ions, 
and sulfate formation. A combined photolysis and radiolysis study on redox processes with organic di- and trisulfides. J. Phys. Chem. 96, 306-314 (1992). doi:10.1021/j100180a058

15. Mason, B.D., Schöneich, C., Kerwin, B.A.: Effect of $\mathrm{pH}$ and light on aggregation and conformation of an IgG1 mAb. Mol. Pharm. 9, 774-790 (2012). doi:10.1021/mp2004719

16. Wang, W., Singh, S., Zeng, D.L., King, K., Nema, S.: Antibody structure, instability, and formulation. J. Pharm. Sci. 96, 1-26 (2007). doi:10.1002/jps

17. Simons, J.: Molecular Anions. J. Phys. Chem. A. 112, 6401-6511 (2008). doi:10.1021/jp711490b

18. Osburn, S., Burgie, T., Berden, G., Oomens, J., O'Hair, R.A.J., Ryzhov, V.: Structure and reactivity of homocysteine radical cation in the gas phase studied by ion-molecule reactions and infrared multiple photon dissociation. J. Phys. Chem. A. 117, 1144-1150 (2013). doi:10.1021/jp304769y

19. Lesslie, M., Lau, J.K.C., Lawler, J.T., Siu, K.W.M., Steinmetz, V., Maître, P., Hopkinson, A.C., Ryzhov, V.: Cysteine Radical/Metal Ion Adducts: A Gas-Phase Structural Elucidation and Reactivity Study. Chempluschem. 81, 444-452 (2016). doi:10.1002/cplu.201500558

20. Parker, W.R., Holden, D.D., Cotham, V.C., Xu, H., Brodbelt, J.S.: Cysteine-Selective Peptide Identification: Selenium-Based Chromophore for Selective S-Se Bond Cleavage with $266 \mathrm{~nm}$ Ultraviolet Photodissociation. Anal. Chem. 88, 7222-7229 (2016).

doi:10.1021/acs.analchem.6b01465

21. Diedrich, J.K., Julian, R.R.: Site selective fragmentation of peptides and proteins at quinone modified cysteine residues investigated by ESI-MS. Anal. Chem. 82, 4006-4014 (2010). doi:10.1021/ac902786q

22. Brunet, C., Antoine, R., Allouche, A.-R., Dugourd, P., Canon, F., Giuliani, A., Nahon, L.: Gas phase photo-formation and vacuum UV photofragmentation spectroscopy of tryptophan and tyrosine radical-containing peptides. J. Phys. Chem. A. 115, 8933-8939 (2011). doi:10.1021/jp205617x

23. Meyer-Lindenberg, A., Domes, G., Kirsch, P., Heinrichs, M.: Oxytocin and vasopressin in the human brain: Social neuropeptides for translational medicine. Nat. Rev. Neurosci. 12, 524538 (2011). doi:10.1038/nrn3044

24. Mozziconacci, O., Schöneich, C.: Photodegragation of Oxytocin and thermal stability of photoproducts. J. Pharm. Sci. 101, 3331-3346 (2012). doi:10.1002/jps

25. Hoffman, M.Z., Hayon, E.: One-Electron Reduction of the Disulfide Linkage in Aqueous Solution. Formation, Protonation, and Decay Kinetics of the RSSR- Radical. J. Am. Chem. Soc. 94, 7950-7957 (1972). doi:10.1021/ja00778a002

26. Tung, T.-L., Stone, J.A.: The Formation and Reactions of Disulfide Radical Anions in Aqueous Solution. Can. J. Chem. 53, 3153-3157 (1975). doi:10.1139/v75-449

27. Milosavljević, A.R., Nicolas, C., Gil, J.-F., Canon, F., Réfrégiers, M., Nahon, L., Giuliani, A.: VUV synchrotron radiation: a new activation technique for tandem mass spectrometry. J. Synchrotron Radiat. 19, 174-178 (2012). doi:10.1107/S0909049512001057

28. Nahon, L., de Oliveira, N., Garcia, G.A., Gil, J.-F., Pilette, B., Marcouillé, O., Lagarde, B., Polack, F.: DESIRS: a state-of-the-art VUV beamline featuring high resolution and variable polarization for spectroscopy and dichroism at SOLEIL. J. Synchrotron Radiat. 19, 508-520 (2012). doi:10.1107/S0909049512010588 
29. Brunet, C., Antoine, R., Dugourd, P., Canon, F., Giuliani, A., Nahon, L.: Formation and fragmentation of radical peptide anions: Insights from vacuum ultra violet spectroscopy. J. Am. Soc. Mass Spectrom. 23, 274-281 (2012). doi:10.1007/s13361-011-0285-7

30. Milosavljević, A.R., Nicolas, C., Lemaire, J., Dehon, C., Thissen, R., Bizau, J.-M., Réfrégiers, M., Nahon, L., Giuliani, A.: Photoionization of a protein isolated in vacuo. Phys. Chem. Chem. Phys. 13, 15432-6 (2011). doi:10.1039/c1cp21211g

31. Sohn, C.H., Gao, J., Thomas, D.A., Kim, T.-Y., Goddard III, W.A., Beauchamp, J.L.: Mechanisms and energetics of free radical initiated disulfide bond cleavage in model peptides and insulin by mass spectrometry. Chem. Sci. 6, 4550-4560 (2015). doi:10.1039/C5SC01305D

32. Ganisl, B., Valovka, T., Hartl, M., Taucher, M., Bister, K., Breuker, K.: Electron detachment dissociation for top-down mass spectrometry of acidic proteins. Chem. - A Eur. J. 17, 44604469 (2011). doi:10.1002/chem.201003709

33. Agarwal, A., Diedrich, J.K., Julian, R.R.: Direct Elucidation of Disulfide Bond Partners Using Ultraviolet Photodissociation Mass Spectrometry. Anal. Chem. 83, 6455-6458 (2011). doi:10.1021/ac201650v

34. Bilusich, D., Bowie, J.H.: Fragmentation of (M-H)- anions of underivatized peptides. Part 2: characteristic cleavages of Ser and Cys and of disulfides and other post-translational modifications, together with some unusual internal processes. Mass Spectrom. Rev. 28, 20-34 (2009). doi:10.1002/mas

35. Thakur, S.S., Balaram, P.: Fragmentation of Peptide Disulfides under Conditions of Negative Ion Mass Spectrometry: Studies of Oxidized Glutathione and Contryphan. J. Am. Soc. Mass Spectrom. 19, 358-366 (2008). doi:10.1016/j.jasms.2007.12.005 
Legends

Figure 1 - [OTSS] ${ }^{2-}$ VUVPD mass spectrum averaged over the full 4.5-16 eV range. In inset, the evolution of the fragmentation ratio with the VUV photon energy (bullets), compared to the spontaneous fragmentation ratio (dashed line).

Figure 2 - [OTSH] ${ }^{2-}$ VUVPD mass spectrum averaged over the full 4.5-16 eV range. In inset, the evolution of the fragmentation ratio with the VUV photon energy (bullets), compared to the spontaneous fragmentation ratio (dashed line).

Figure 3 - [OTSS] "- VUVPD mass spectrum averaged over the full 4.5-16 eV range. In inset, the evolution of the fragmentation ratio with the VUV photon energy (bullets), compared to the spontaneous fragmentation ratio (dashed line).

Figure 4 - [OTSH] *- VUVPD mass spectrum averaged over the full $4.5-16 \mathrm{eV}$ range. In inset, the evolution of the fragmentation ratio with the VUV photon energy (bullets), compared to the spontaneous fragmentation ratio (dashed line).

Scheme 1 - Oxytocin sequence

Scheme 2 - Two-colors (UV+VUV) sequence

Scheme 3 - Proposed mechanism for the loss of $\mathrm{S}_{2} \mathrm{H}^{\circ}$ from [OTSS]

Scheme 4 - Proposed mechanism for the generation of ion at $m / z 886$ from [OTSS] ${ }^{*}$

Scheme 5 - Proposed mechanism for the generation of ion at $m / z 853$ from [OTSS] $]^{*}$

Scheme 6 - Proposed mechanism for the loss of $\mathrm{NH}_{3}$ from [OTSH] ${ }^{*}$

Scheme 7 - Proposed mechanism for the formation of $b_{5}$ fragment ion from [OTSH] ${ }^{*}$ 


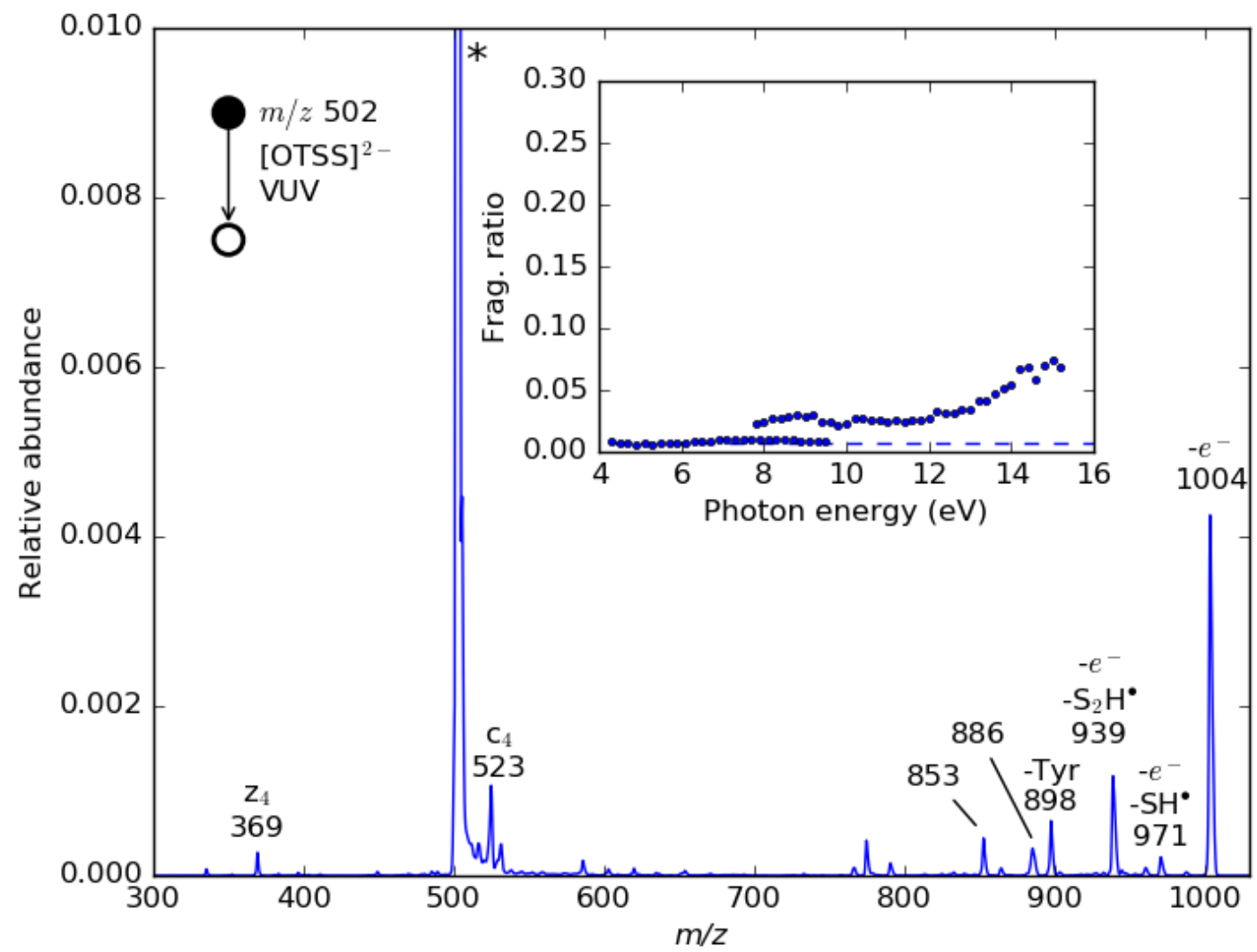

Figure 1 


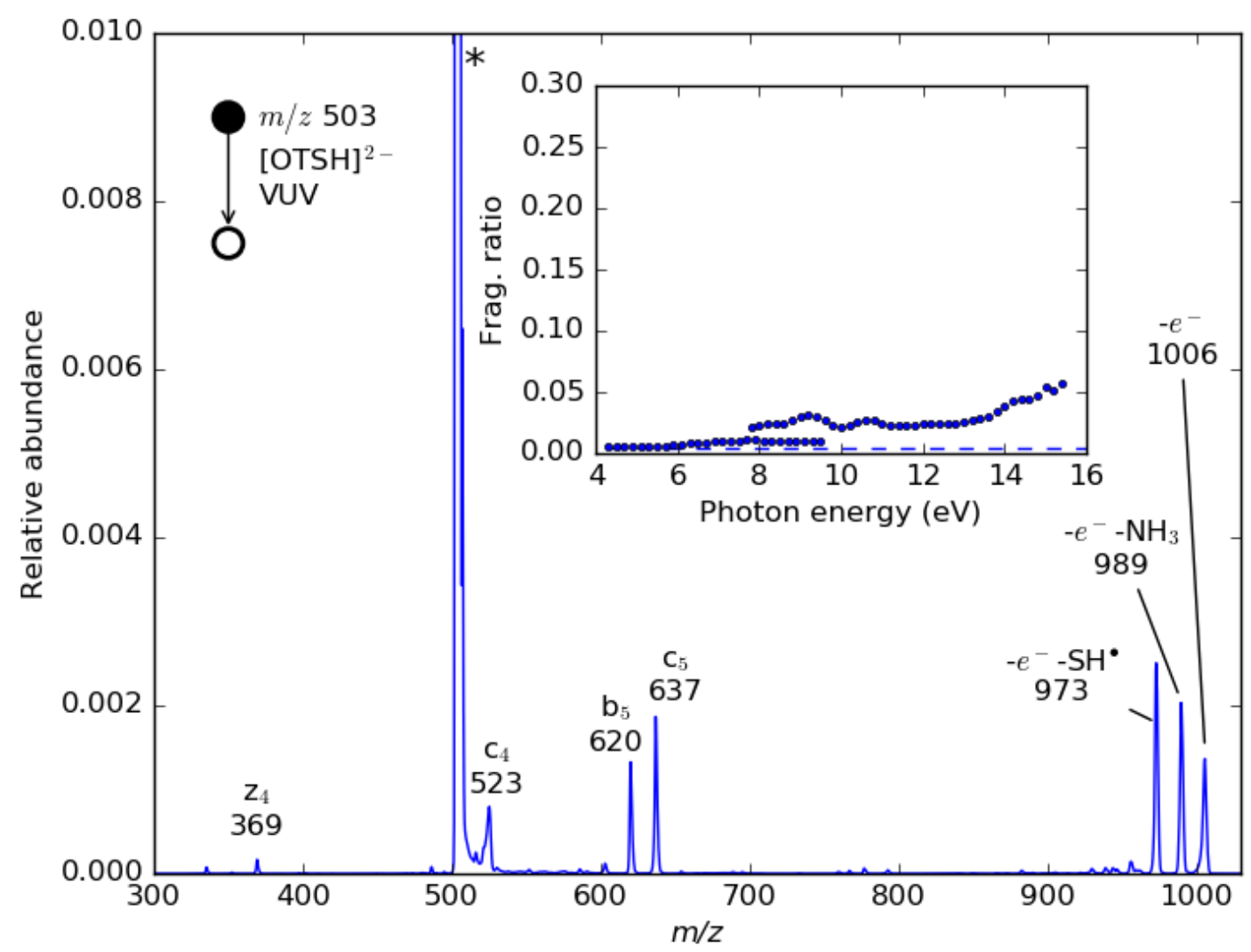

Figure 2 


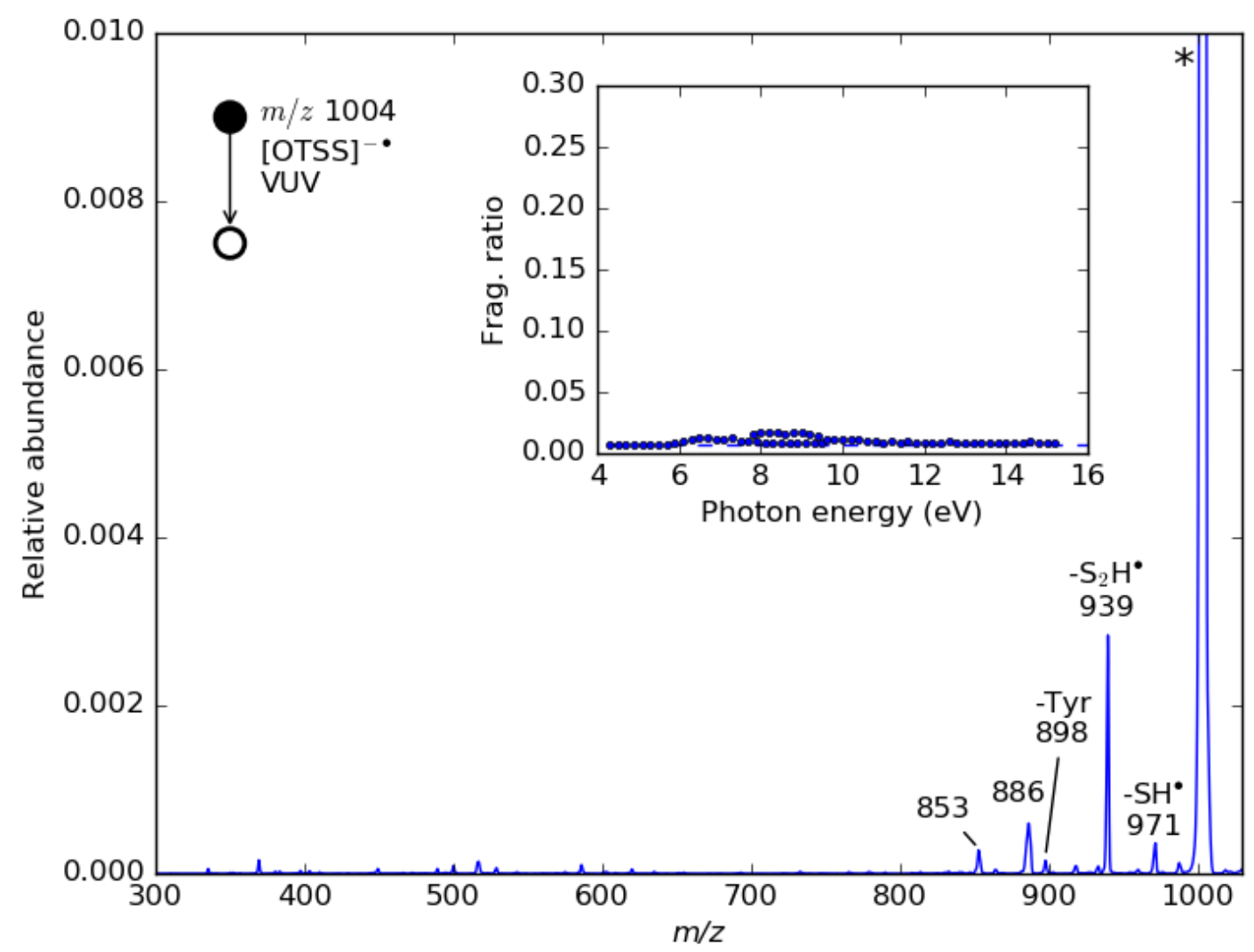

Figure 3 


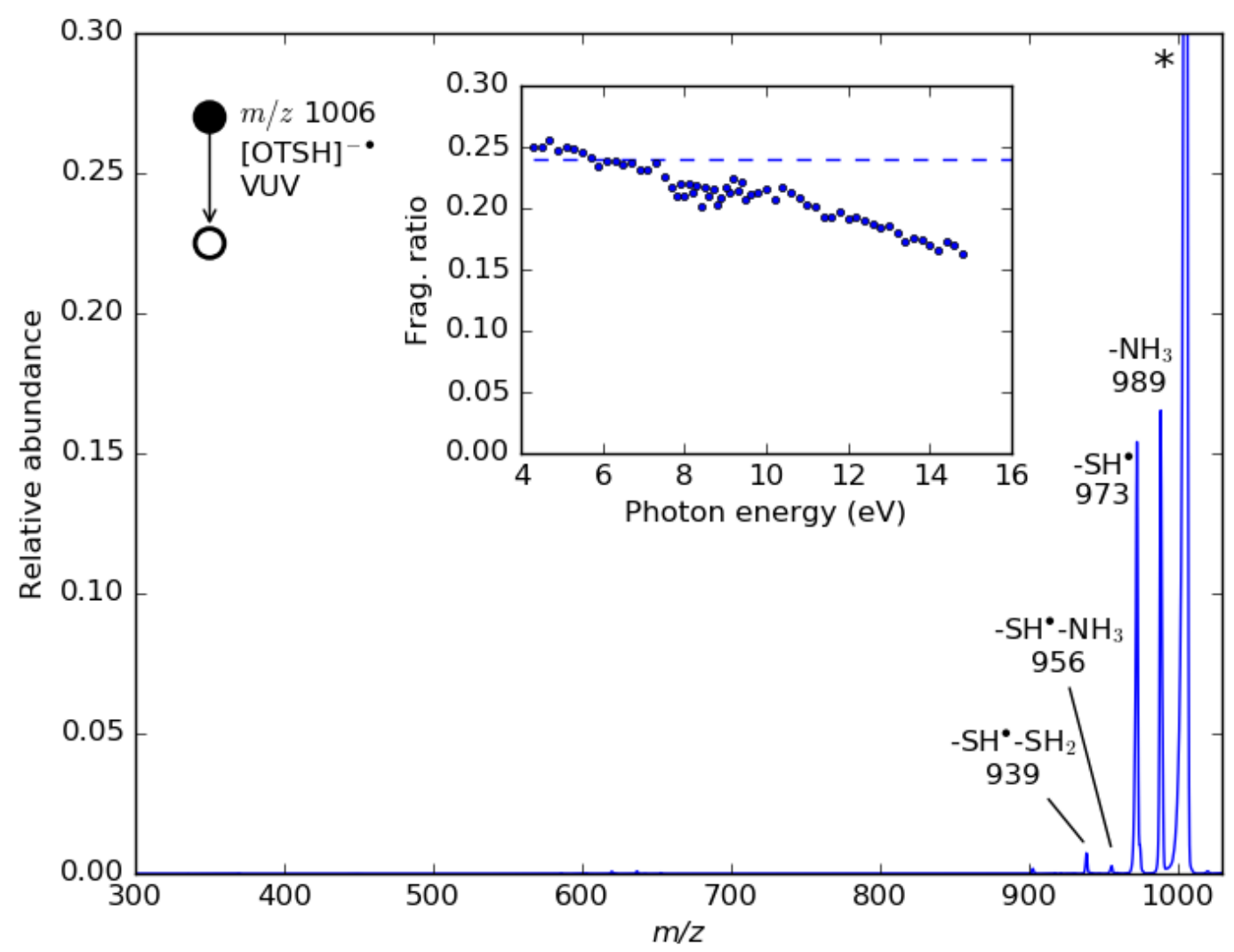

Figure 4 


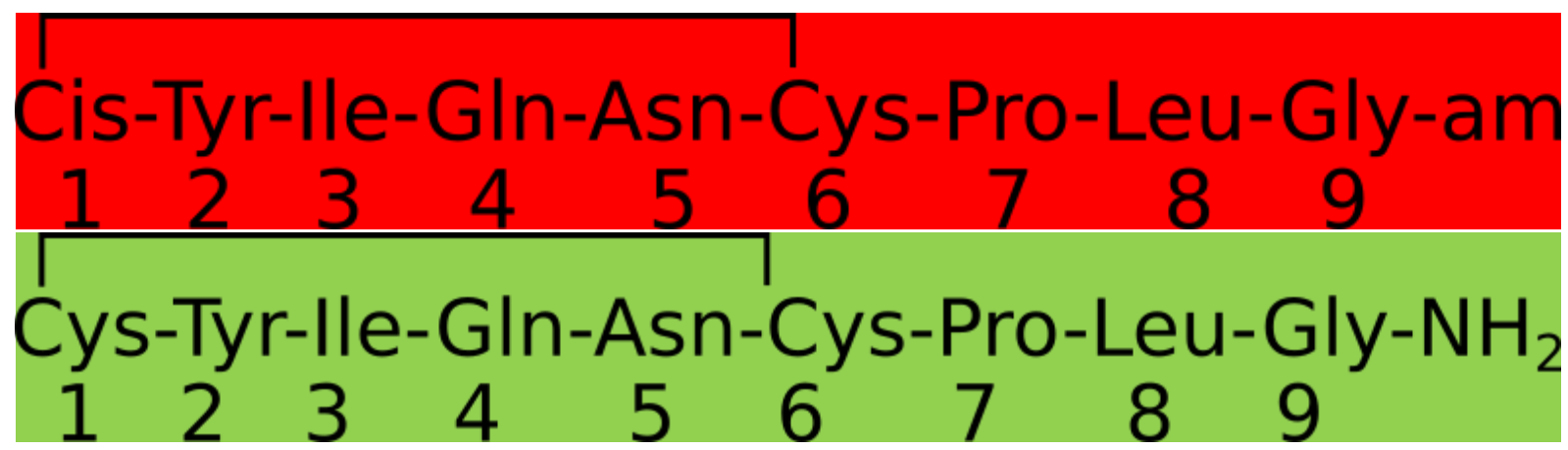

Scheme 1

5

6

7

8

9

10

Scheme 2 
7

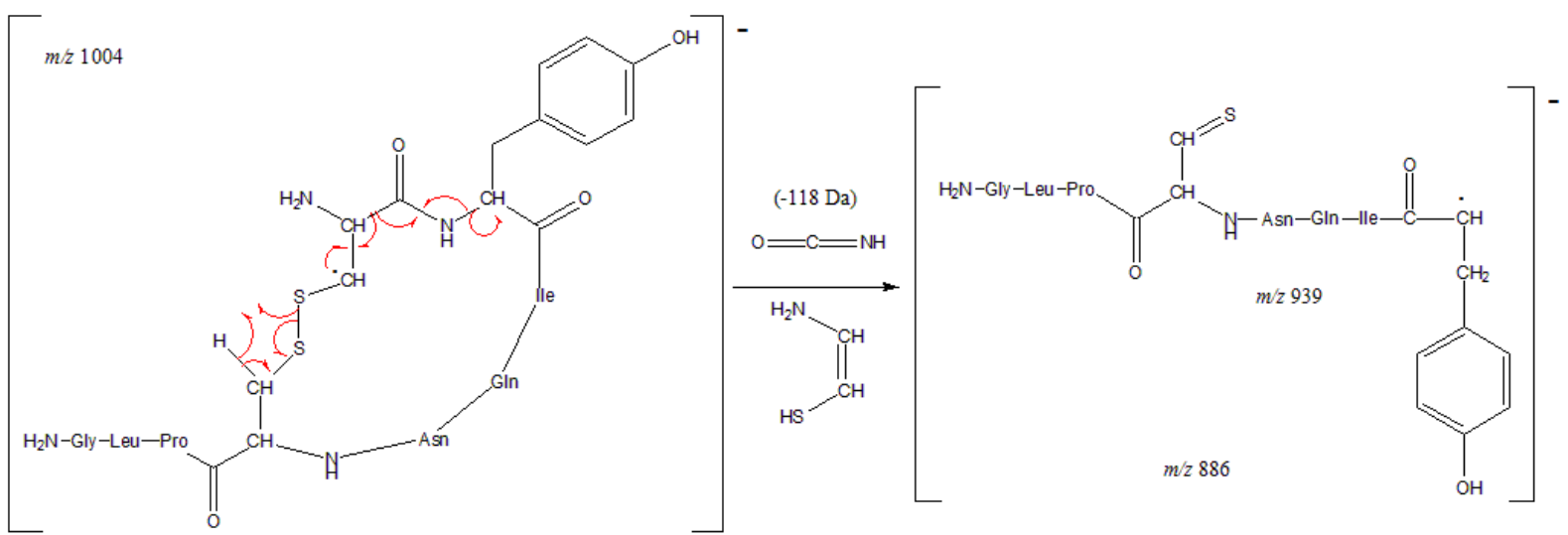

Scheme 4

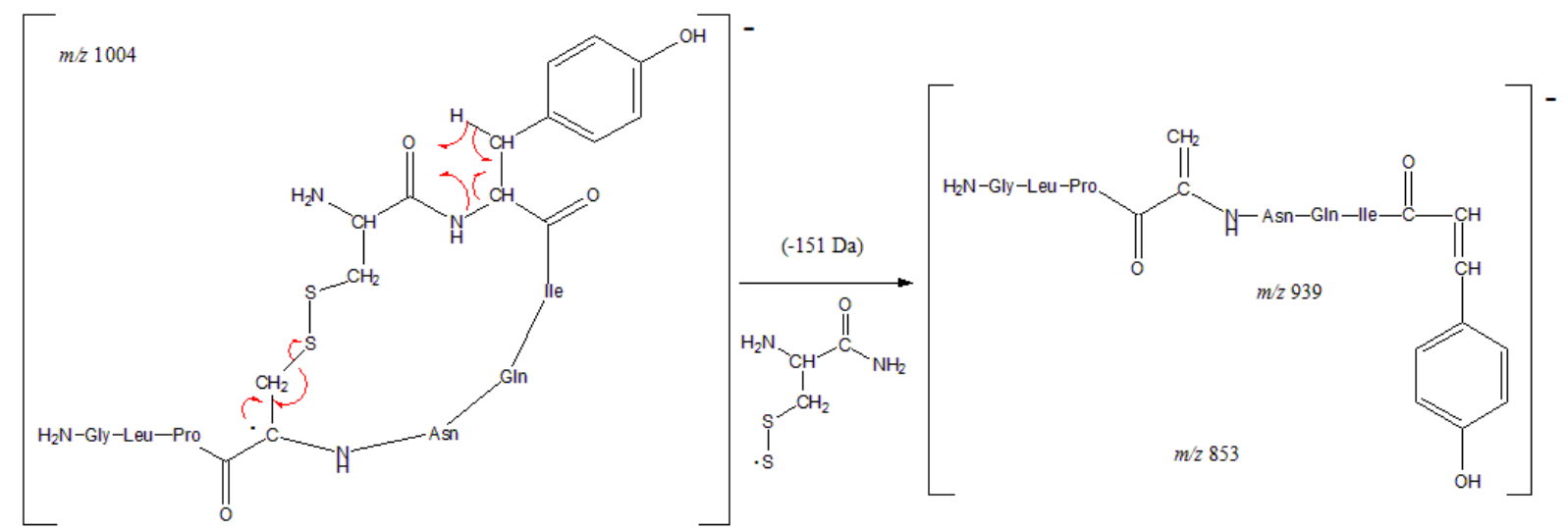

\section{Scheme 5}

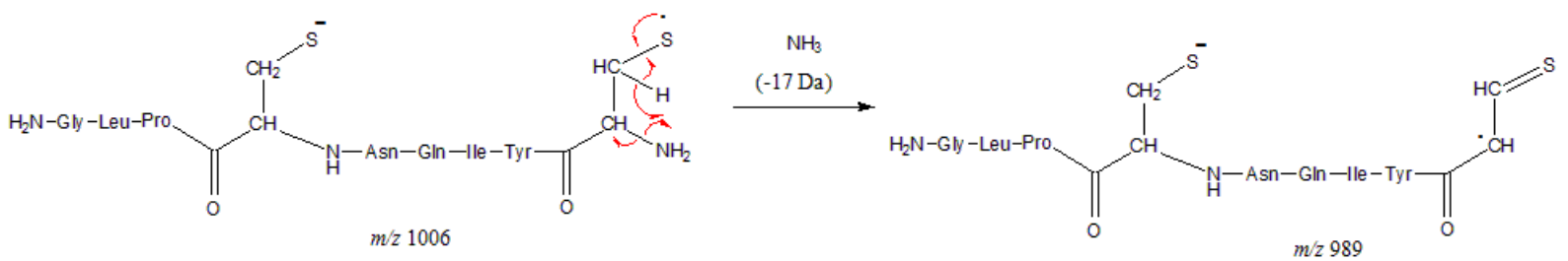

Scheme 6

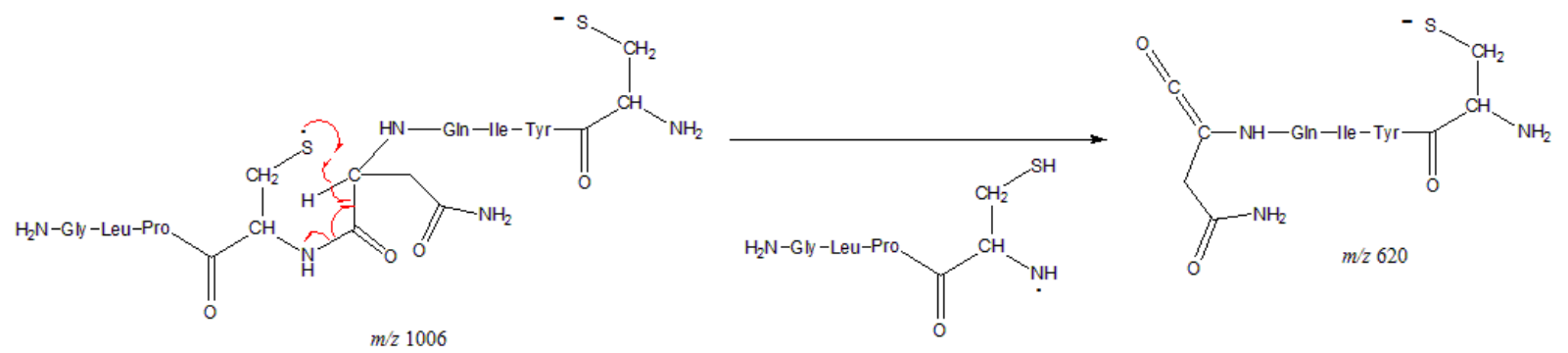

Scheme 7 
2 The supplementary material provided contains:

3

(0) Additional mechanisms proposed for the fragmentation of Oxytocin radical anions

(1) High resolution CID data on OTSS and OTSH anions,

(2) Low resolution CID data on OTSS and OTSH radical anions, Both presented and discussed in terms of differences between fragmentations of radical vs. nonradical anions.

(3) Synchrotron Soleil flux and evaluation of the normalization of fragmentation ratios w.r.t the flux

(0) Additional mechanisms proposed for the fragmentation of Oxytocin radical anions

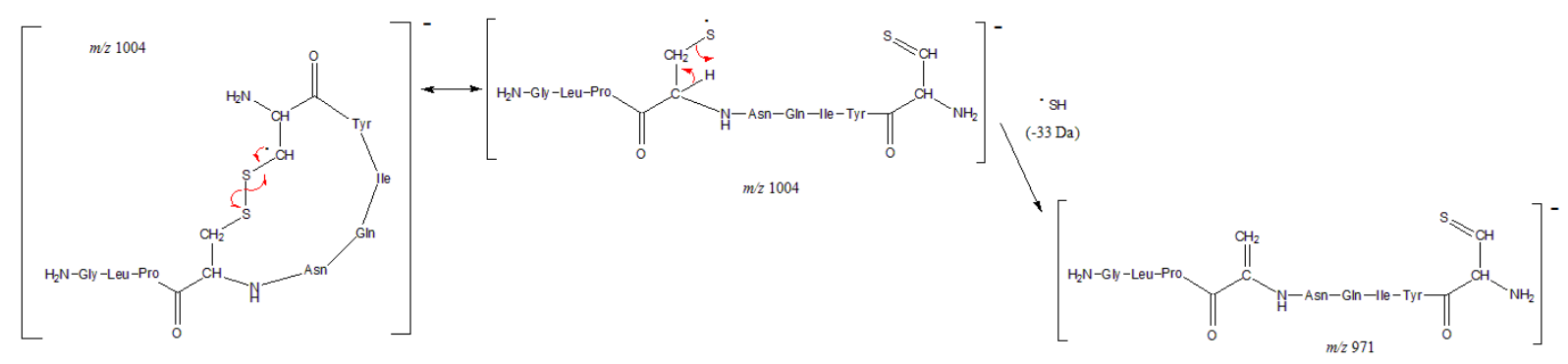

Scheme S1 - Proposed mechanism for the loss of SH• from [OTSS]

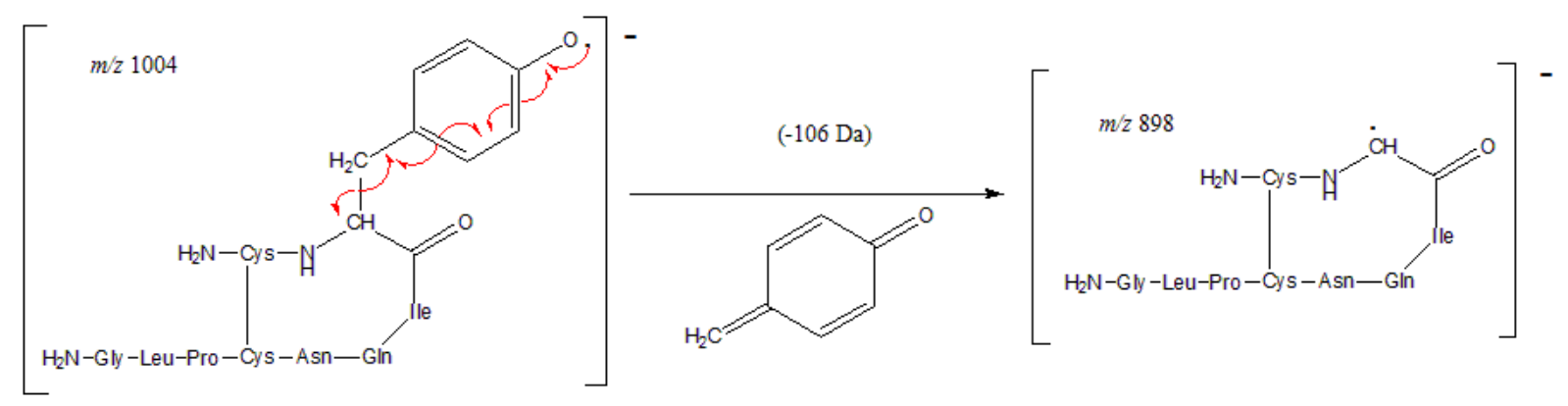

Scheme S2 - Proposed mechanism for the loss of Tyrosine side-chain from [OTSS] ${ }^{\bullet-}$ 
2

4

5

6

8

9

10

13

14

15

16
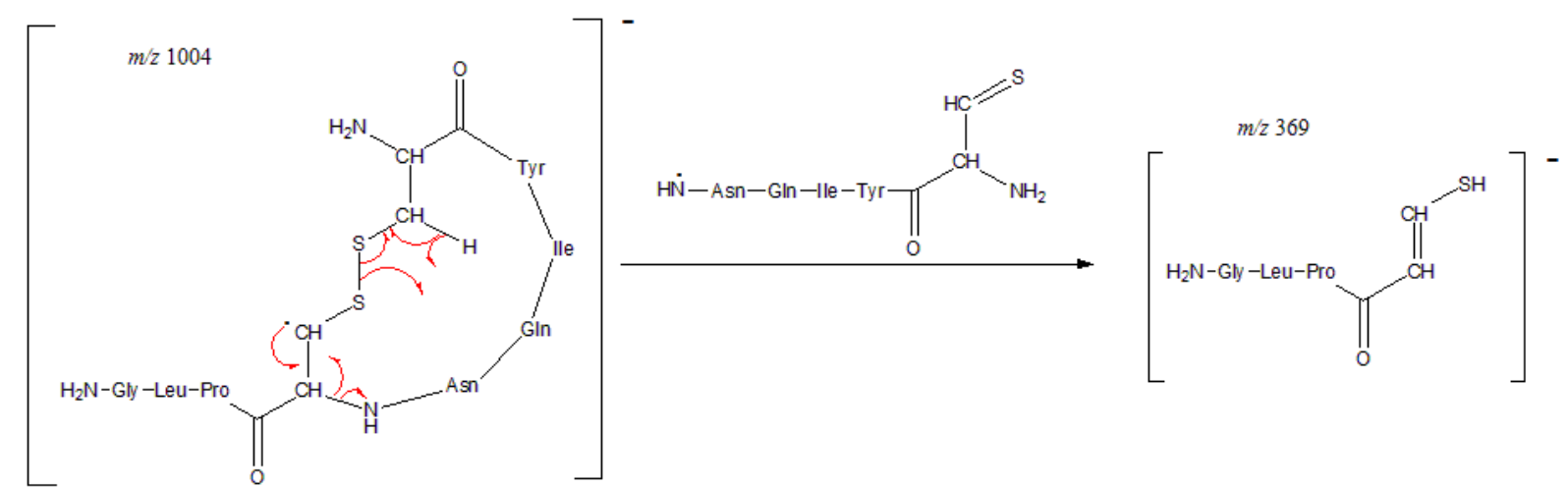

Scheme S3 - Proposed mechanism for the generation of $\mathrm{z}_{4}$ ion at $\mathrm{m} / \mathrm{z} 369$ from [OTSS] ${ }^{\bullet}$
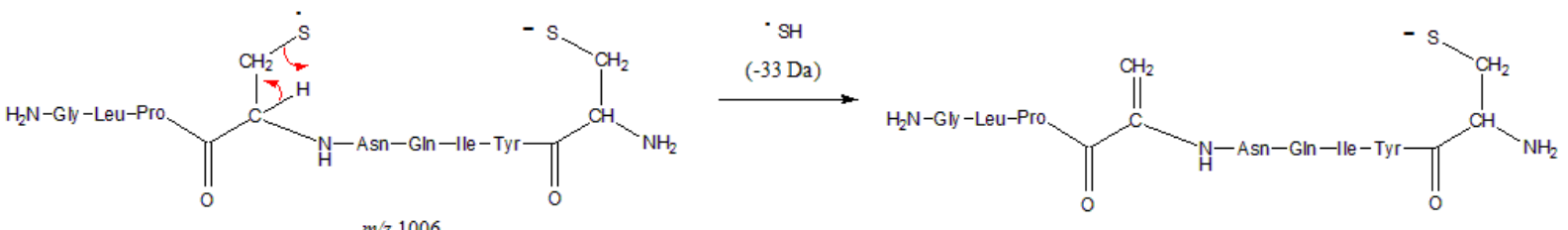

Scheme S4 - Proposed mechanism for the loss of $\mathrm{SH}^{\bullet}$ from [OTSH] -

$m / 2973$

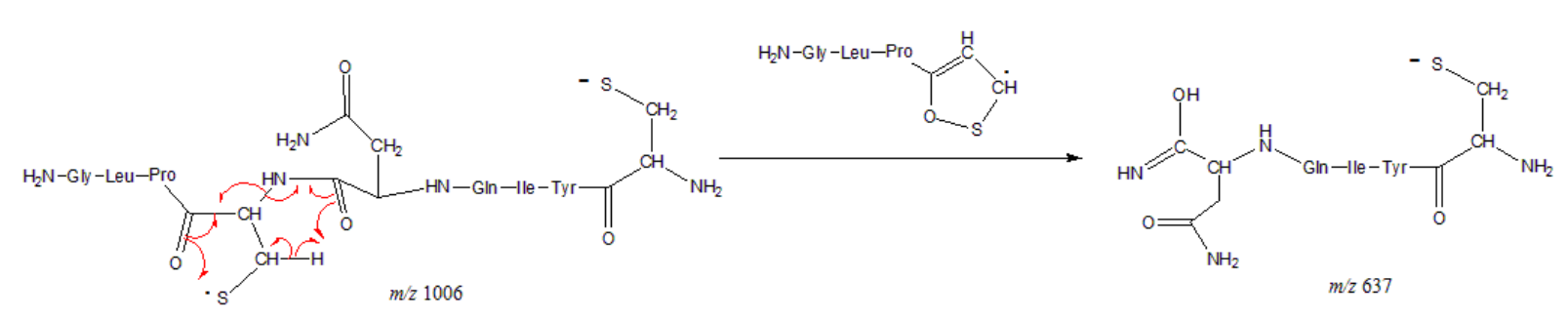

Scheme S5 - Proposed mechanism for the formation of $c_{5}$ fragment ion from [OTSH]

\section{2}

\section{4 (1 \& 2) MS of radicals vs. non-radicals}

5 The analysis of the fragmentation behavior of both OTSS and OTSH radical anions and their

6 comparison with their singly charged (non-radical) anion counterpart reveals significant differences. 


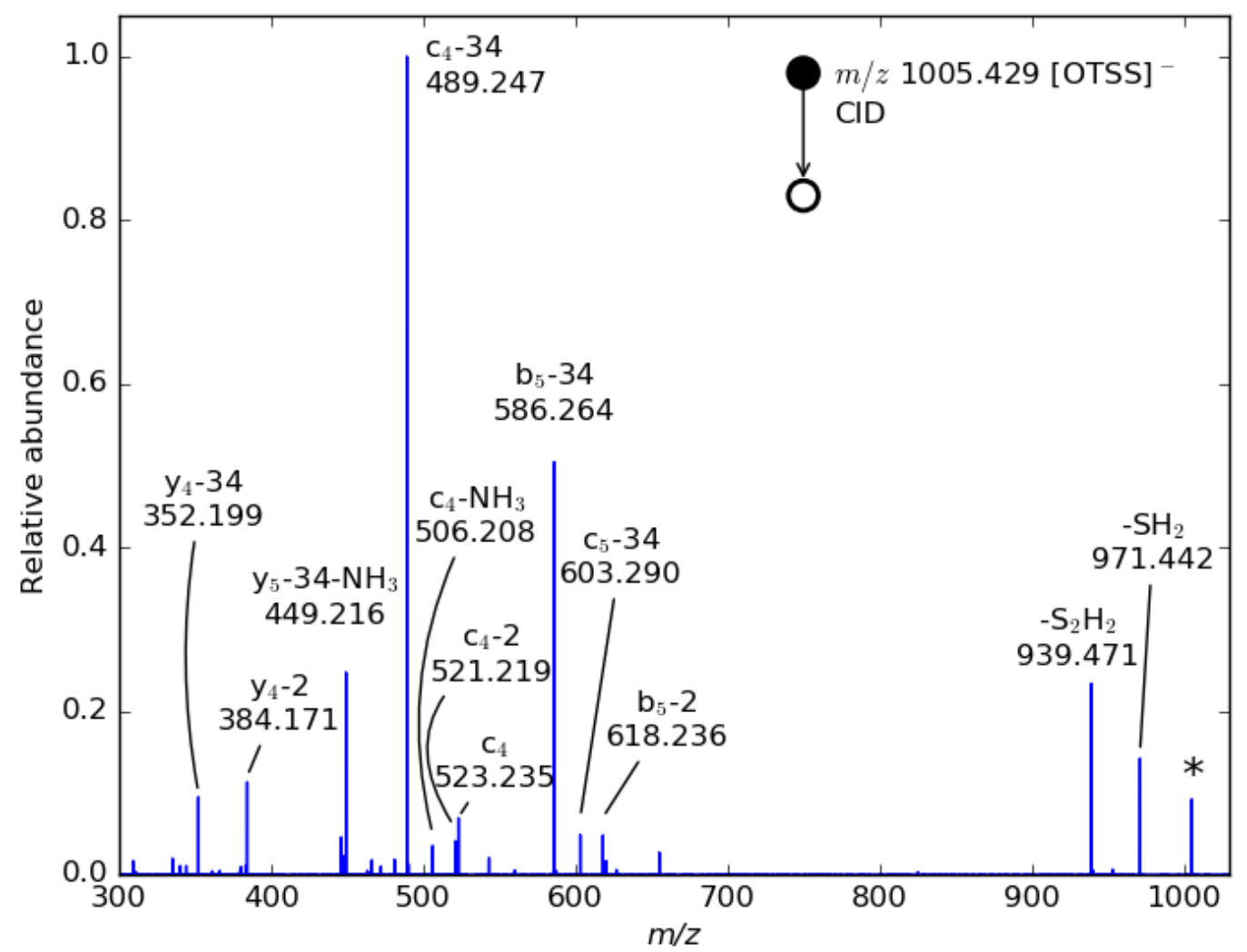

Figure S1 - [OTSS] CID spectrum

The CID spectrum of non-radical singly charged anions [OTSS] ${ }^{-}$at $m / z 1005.429$ is presented in Figure S1. The negative charge is a priori on tyrosine at position 2 in the sequence. The neutral loss of $\mathrm{S}_{2} \mathrm{H}_{2}$ ($65.958 \mathrm{Da}$ ) from the precursor ion, observed at $\mathrm{m} / \mathrm{z} 939.471$, confirmssupports the hypothesis of the initial presence of an intact disulfide bridge. Scheme $\mathrm{S} 6$ displays the proposed mechanism involving 1,3-H transfers from the $\mathrm{C}_{\alpha}$ of the two cysteines. Neutral loss of $\mathrm{SH}_{2}(-33.988 \mathrm{Da})$ from the precursor ion is also observed at $m / z 971.442$ (see Scheme S7), but it is reported for reduced cysteines as well as for intact disulfide bridges $[34,35]$ thus cannot be used as diagnostics. However, $b_{n}$ and $c_{n}$-like fragments are observed for $n=4$ and 5 with particular $-2 /-34$ losses with regards to the classical fragments. This specific pattern reflects mechanisms involving the opening of an intact bridge. Indeed, when $\mathrm{SH}_{2}$ is lost from an intact disulfide bridge, it results from a 1,3-H transfer from $\mathrm{C}_{\beta}$ of one cysteine to the sulfur of the other cysteine (Scheme S7). Thus, one side gains one $\mathrm{H}$ before losing $\mathrm{SH}_{2}$ : that can be seen as a -34 loss with regards to the reduced cysteine. Whereas the side that retains a sulfur loses one $\mathrm{H}$, yielding the thioaldehyde structure $\mathrm{Cys}_{\beta} \mathrm{H}=\mathrm{S}$ which is equivalent to a $-2.016 \mathrm{Da}$ loss with regards to cysteine. This $\mathrm{H}$ transfer can occur in either direction: when the $\mathrm{Cys}_{\beta} \mathrm{H}=\mathrm{S}$ moiety is on Cys1 (Scheme S7), consecutive backbone fragmentation will lead to $\mathrm{N}$-term fragments with a 2.016 Da shift from the classical fragments (Scheme $S 8$ - top). These ions, annotated $b_{5}-2$ and $c_{4}-2$, are detected at $m / z 618.236$ and $m / z 521.219$, respectively. Then, the associated C-term fragments present a -33.988 Da shift $\left(y_{5}-34-\mathrm{NH}_{3}\right.$ at $m / z 449.216$ and $\mathrm{y}_{4}-34$ at $m / z$ 352.199). On the contrary, when the $\mathrm{Cys}_{\beta} \mathrm{H}=\mathrm{S}$ moiety is on $\mathrm{Cys} 6$ (Scheme $\mathrm{S} 8$ - bottom), $\mathrm{N}$-term fragments display a $-33.988 \mathrm{Da}$ shift ( $c_{5}-34$ at $m / z$ 603.290, $b_{5}-34$ at $m / z 586.264$ and $c_{4}-34$ at $m / z 489.247$ ), while C-term fragments display a -2.016 Da shift ( $\mathrm{y}_{4}-2$ at $m / z$ 384.171). This -2 loss is then specific for mechanisms involving the dissociation of the disulfide bridge and validates the presence of an intact disulfide bridge on the 
1 OTSS anion. The non-negligible presence of $y$-fragments might be an indication that the negative 2 charge can be shifted from the initial tyrosynate to another side chain or to the backbone upon 3 activation. $\mathrm{NH}_{3}(-17.027 \mathrm{Da})$ losses are also observed for both $\mathrm{c}_{4}$ and $\mathrm{y}_{5}$ fragment ions.

4

5

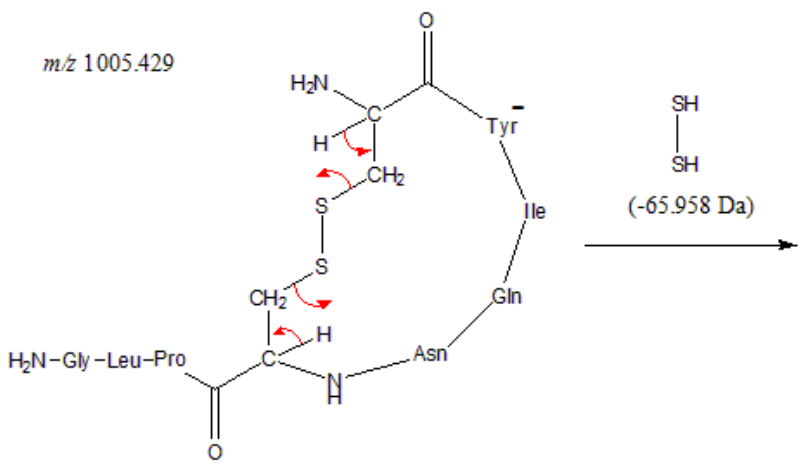

Scheme S6 - Proposed mechanism for $\mathrm{CID}$ of $\mathrm{S}_{2} \mathrm{H}_{2}$ from [OTSS]

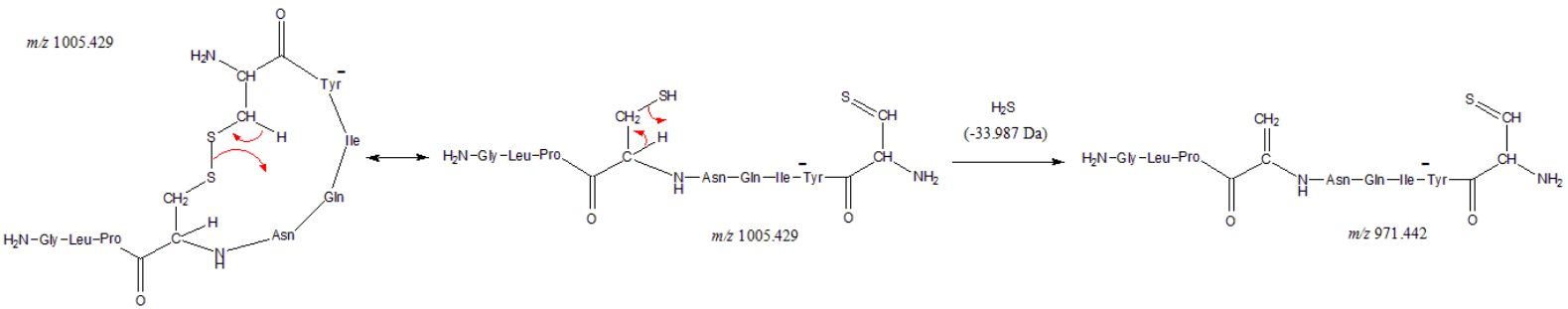




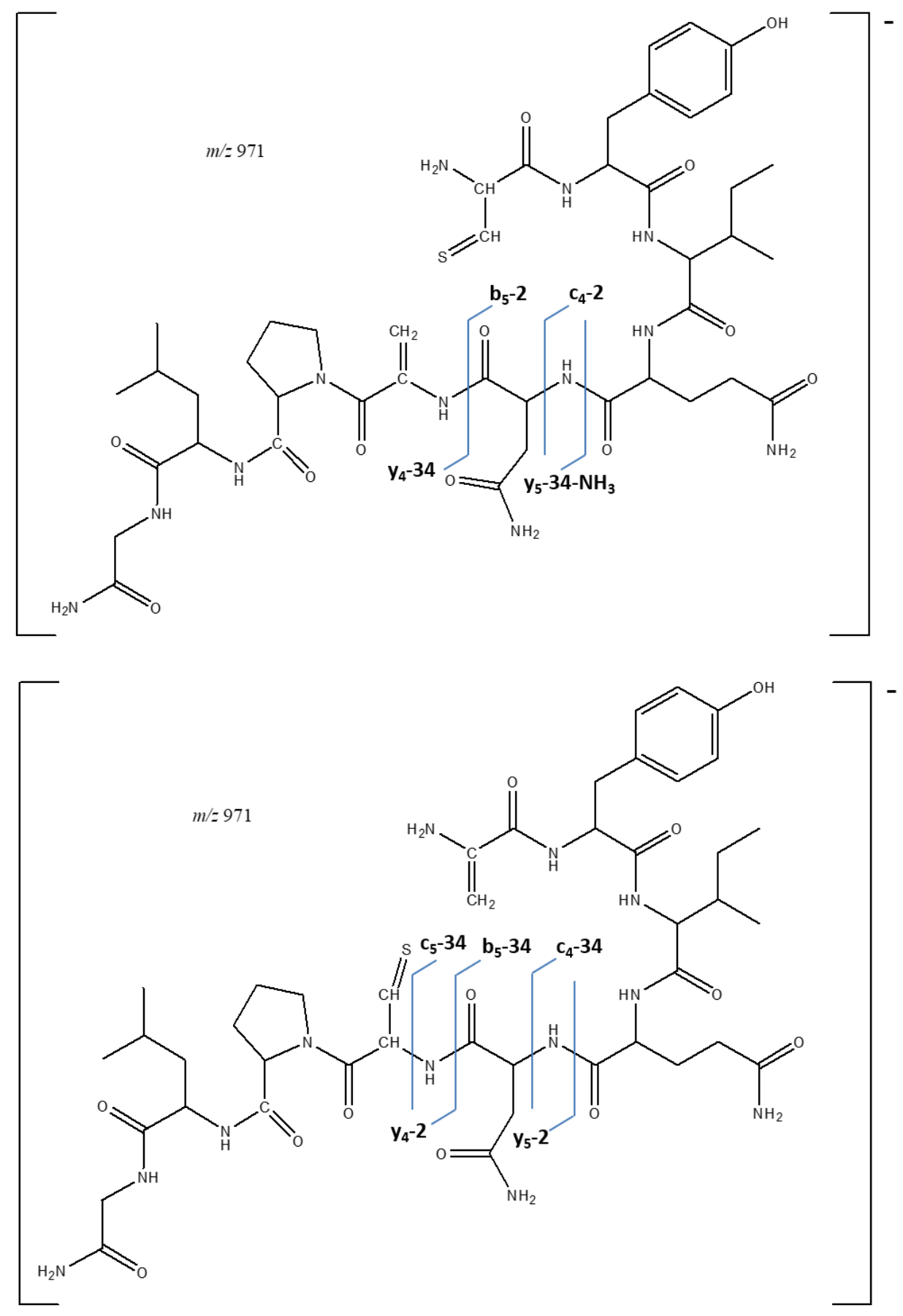




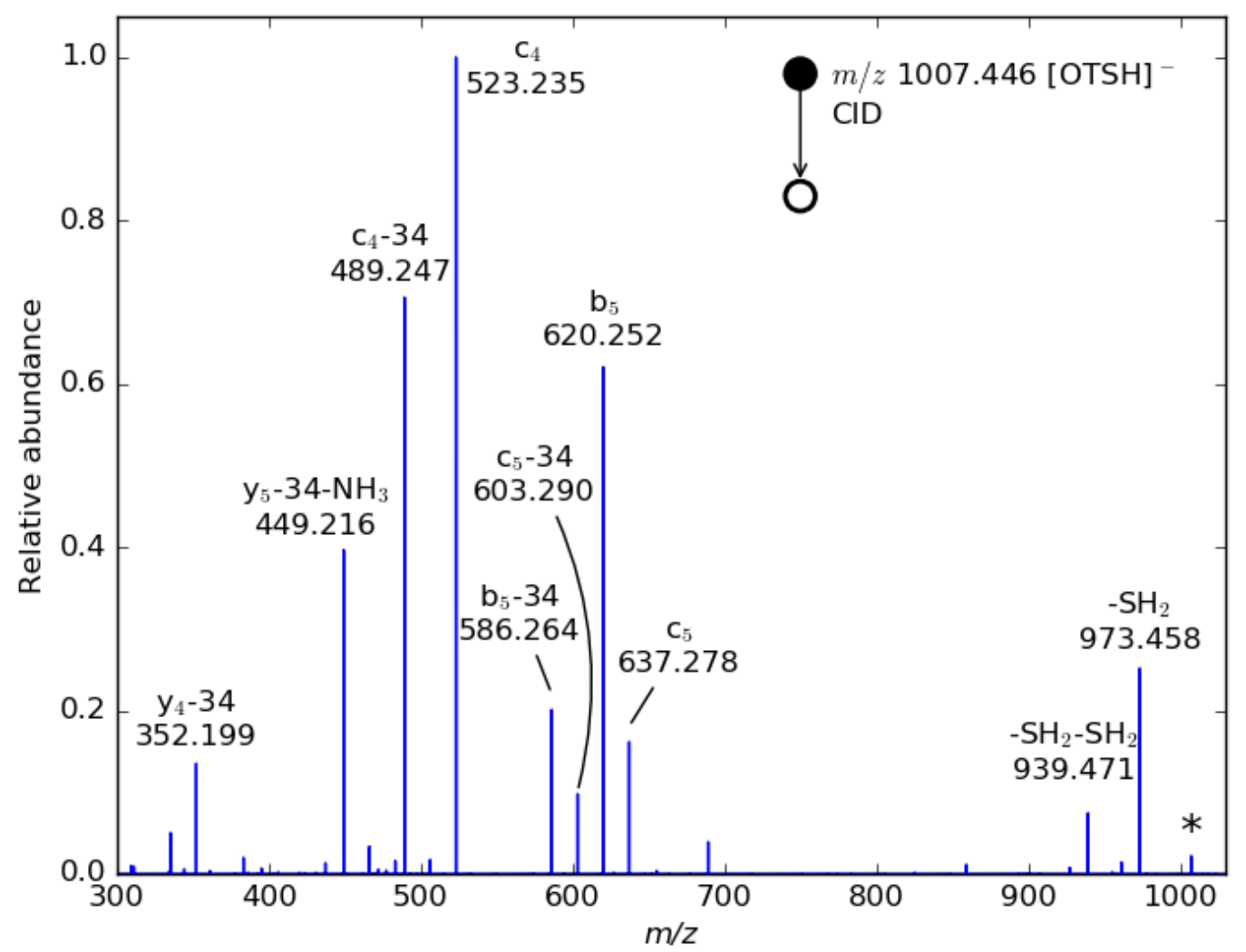

1

Figure S2 - [OTSH]- CID spectrum

The CID spectrum of [OTSH] non-radical singly charged anion, at $m / z 1007.446$ is shown in Figure S2. Neutral losses of successively one and two $\mathrm{SH}_{2}(-33.988 \mathrm{Da}$ and $-67.975 \mathrm{Da}$ ) via 1,3 proton transfer from the $C_{\alpha}$ of the two cysteines are observed from the precursor ion at $m / z 973.458$ and $m / z$ 939.471, respectively. The second $\mathrm{SH}_{2}$ elimination requires a proton transfer from, for instance, the neutral tyrosine to the thiolate upon activation. Both $\mathrm{N}$ - and $\mathrm{C}$-term fragments are observed, with for each fragment a possible loss of $\mathrm{SH}_{2}\left(b_{5}, b_{5}-34, c_{4}, c_{4}-34, c_{5}, c_{5}-34, y_{5}-34, y_{4}-34\right)$. Remarkably, $y$ fragments always come with a -34 loss, which suggests that $\mathrm{Cys} 6$ is preferentially remaining under its $\mathrm{SH}$ form. No -2 loss is observed, as expected: this confirmsprovides evidence that the disulfide bridge was indeed reduced in OTSH and remains open in the singly charged anion. 


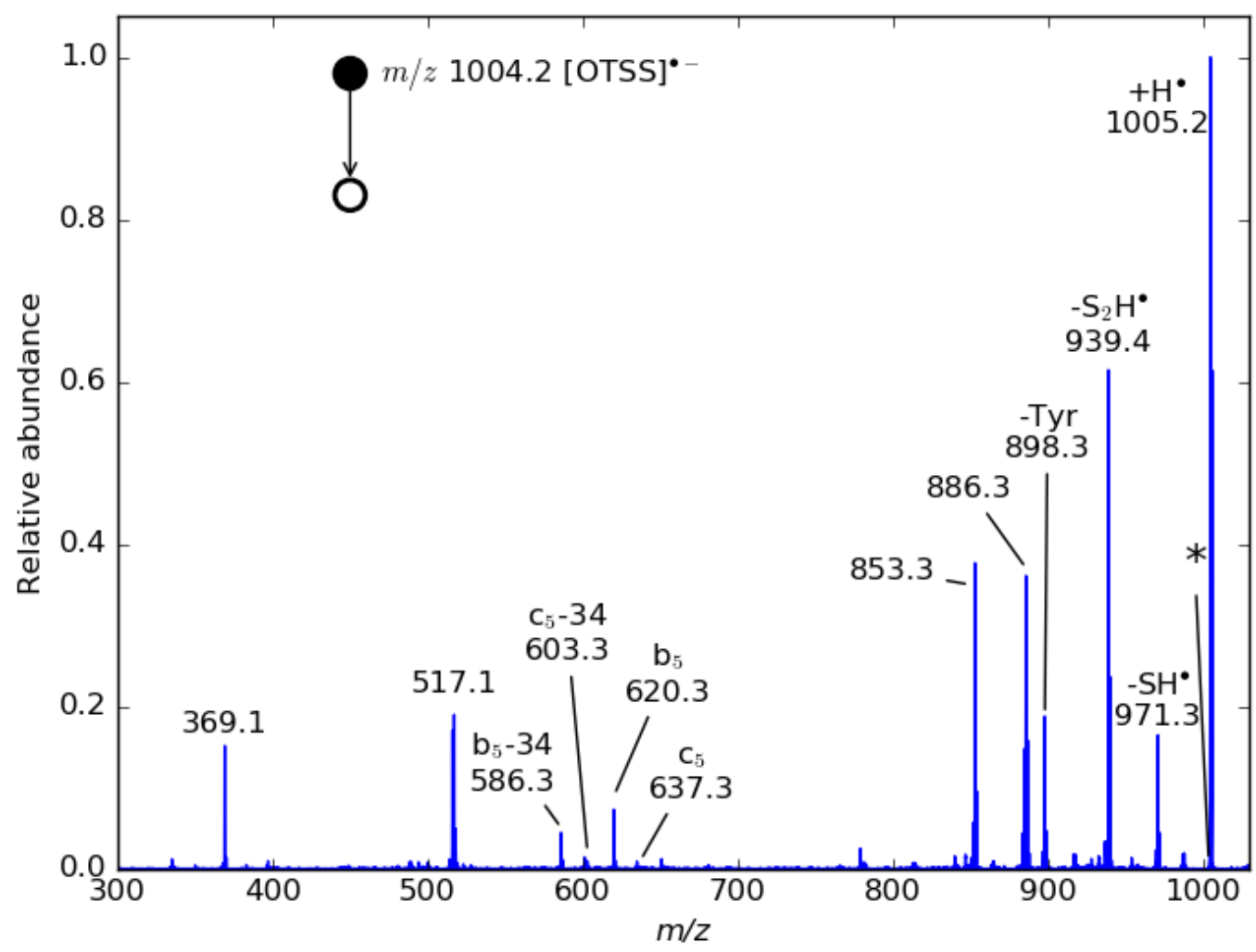

1 


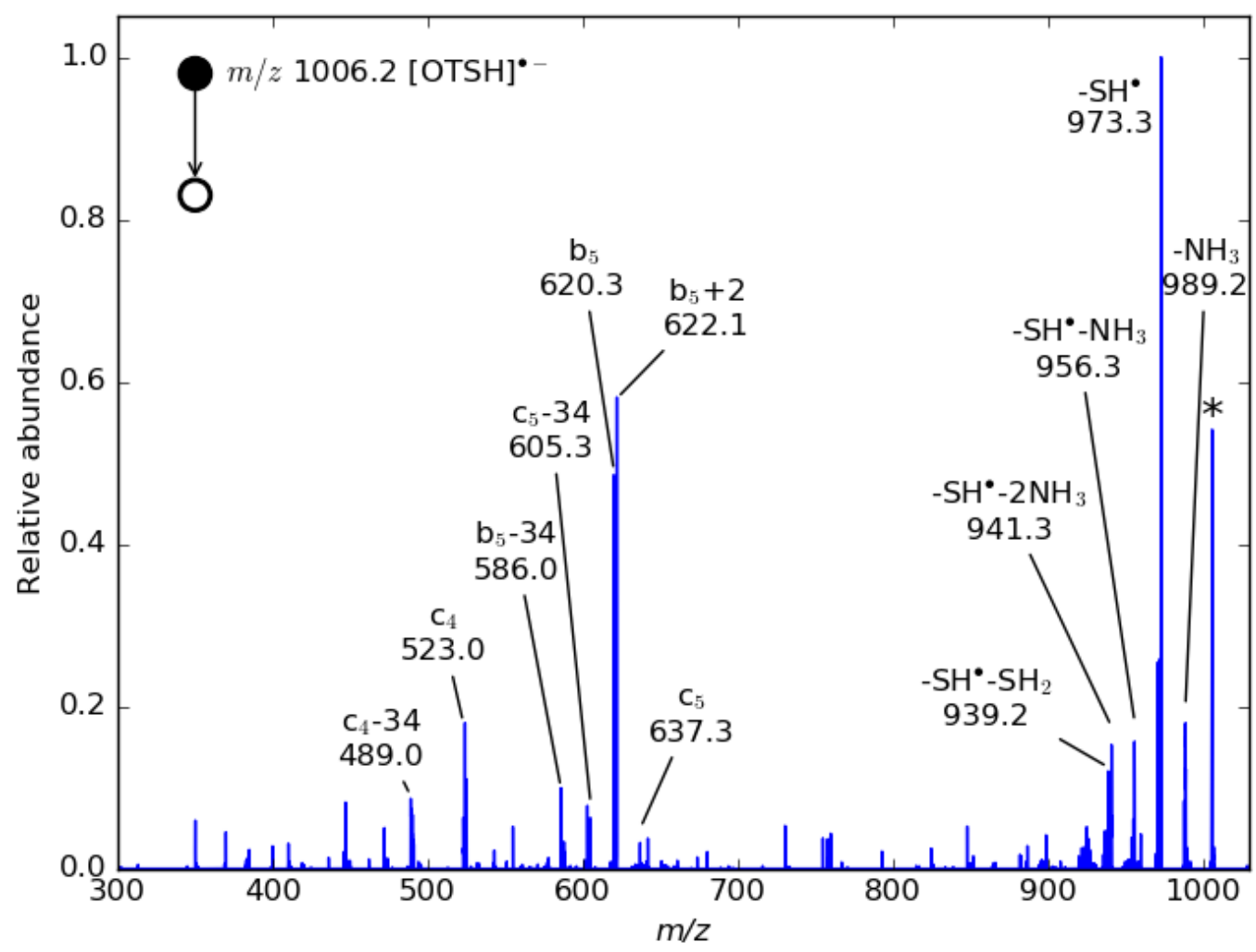

1

Figure S4 - [OTSH] •- CID spectrum

The CID spectra of the radical anions produced by electron detachment from oxidized and reduced OT dianions are respectively presented in Figure S3 and Figure S4. Remarkably, the CID spectrum of [OTSS]"- mass selected at $m / z$ 1004.1 (Figure S3), displays a major component at $m / z$ 1005.1, suggesting that [OTSS] ${ }^{-*}$ is very reactive towards $\mathrm{H}$-atom transfer from a molecule in the ion trap (most likely traces of $\mathrm{H}_{2} \mathrm{O}$ remaining from the ESI process). The radical in [OTSS] ${ }^{*}$ is a priori located on the tyrosine side chain due to the low ionization energy of the phenolate moiety $(2.3 \mathrm{eV})$. In addition to fragments observed after vacuum UV irradiation which are already discussed in the main document, another intense fragment ions is detected at $m / z$ 517.1. This ion is not observed in the CID spectrum of the non-radical anion and is thus produced by radical-induced fragmentation. The proposed mechanism for its formation involved first a $\mathrm{H}$ abstraction on $\mathrm{Cys}_{1} \mathrm{C}_{\beta}$, followed by the radical-induced cleavages of Cys1 S-C bond and Asn5 C-N bond (Scheme S9). Eventually, some $b_{5}, b_{5}-$ 34 and $\mathrm{c}_{5}-34$ fragment ions are detected at their expected mass, respectively $\mathrm{m} / \mathrm{z} 620.1, \mathrm{~m} / \mathrm{z} 586.1$ and $m / z 603.1$ as observed from the [OTSH] ${ }^{-}$anion. This suggests that they are not radical. One possibility is that those fragments come from the $\mathrm{m} / \mathrm{z} 1005.1$ product ion, where the disulfide bridge is not closed anymore. 


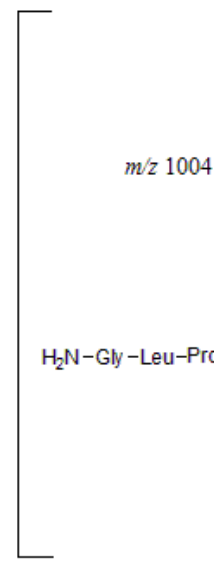

The CID spectrum of [OTSH] ${ }^{*}$ radical anion at $m / z 1006.2$ is displayed in Figure S4. It can be noted that there is no $\mathrm{C}$-term fragment, suggesting that from the bis-thiolate dianion, the radical is more stabilized on Cys6, leaving the charge on Cys1. Apart from the major $\mathrm{SH}^{\cdot}$ and $\mathrm{NH}_{3}$ loss already discussed in the main document, there are important contributions assigned to $b_{5}+2, b_{5}, b_{5}-34, c_{5}, c_{5}-$ $34, c_{4}$ and $c_{4}-34$. The latter six fragments are identical to those formed from the OTSH singly charged anion, which confirms supports the preferential localization of the radical on Cys6. Fragment ion $b_{5}+2$ detected at $\mathrm{m} / \mathrm{z} 622.1$ is however very intense and could come from the inverse 1,4-H transfer between carbonyl on Asn 5 and $\mathrm{C}_{\beta} \mathrm{H}_{2}$ on Cys6, induced by the presence of the radical on Cys6 (Scheme S10).
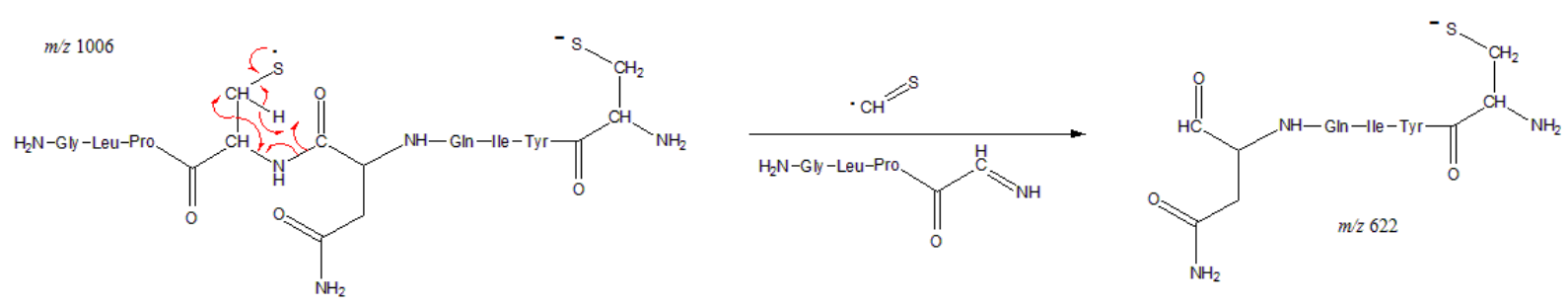

\section{(3) SOLEIL synchrotron flux at the DESIRS Beamline}

Soleil fluxes present large amplitudes of variation, in particular on the sides of each filter/energy range (see curves below). Depending on the filter, this flux is normally very stable day to day. However, when we normalize by the flux, we essentially see the flux profile, which indicates that we "over-correct". Thus the choice was made not to correct for the flux, in order to avoid adding extra noise and so that we could display and discuss actual fragmentation ratios instead of arbitrary units. This is, of course, at the expense of precision and we do limit the discussion to large trends. The point is to focus the attention on the generally low fragmentation levels rather than on local variations, artificial features and non-overlapping curves between the $4-9 \mathrm{eV}$ and $8-15 \mathrm{eV}$ ranges. 

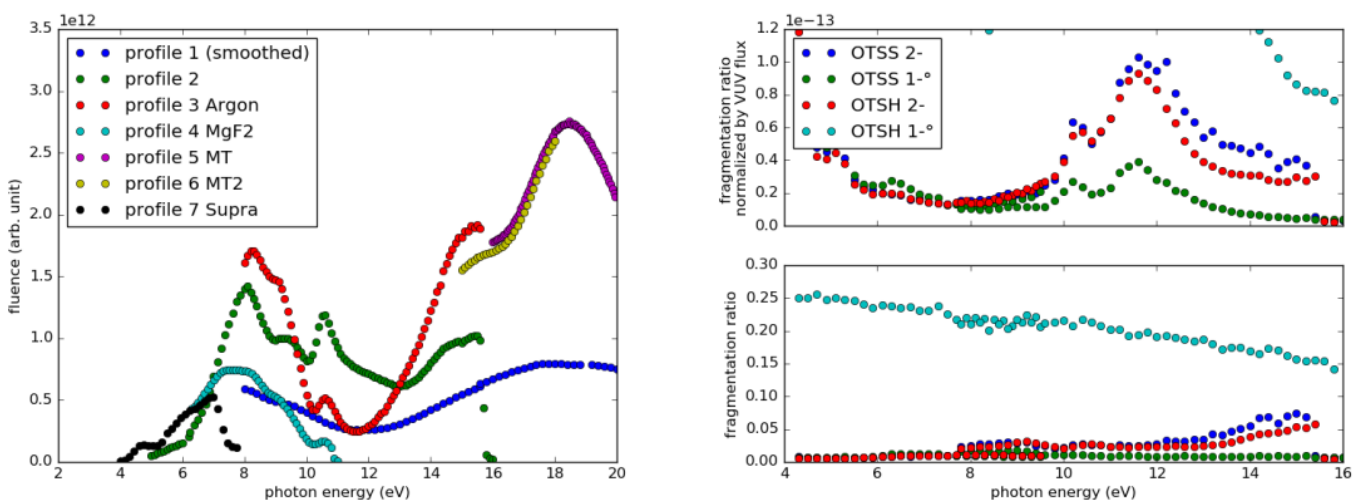

Figure S5 - (Left) Various SOLEIL synchroton flux profiles depending on the date and the filters used. (Right) Comparison between OT fragmentation ratios with (upper panel) and without normalization by SOLEIL flux (lower panel). 